\title{
Comprehensive derivatization of thioviridamides by heterologous expression
}

Kei Kudo, Hanae Koiwai, Noritaka Kagaya, Makoto Nishiyama, Tomohisa Kuzuyama, Kazuo Shin-ya, and Haruo Ikeda

\section{Supporting Information}

Strains and cultivations

Experimental procedures

1. Construction of gene cluster carrying amino acid substitution in a gene encoding precursor peptide

2. Isolation of TVA-like compounds

3. Cytotoxicity assay

Supplemental figures and tables

Figure S1. Designed derivatives and by-products

Figure S2. MS/MS analysis of the thioviridamide derivatives

Figure S3. Proposed biosynthetic pathway for prethioviridamide

Figure S4. TVA derivatives subjected to cytotoxicity assay

Figure S5. Viability of cells treated with TVA derivatives

Table S1. Primers used in this study

Table S2. Designs and productivities of prethioviridamide derivatives

Table S3. Designs and productivities of neothioviridamide derivatives

Reference 


\section{Strains and cultivations}

The growth of Escherichia coli strains, DH5 $\alpha$ and GM2929 hsdS::Tn10 ${ }^{1}$, were used LB containing $10 \mathrm{~g}$ of tryptone, 5

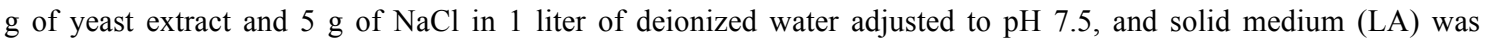
solidified by adding $15 \mathrm{~g}$ of agar to 1 liter of LB medium. In the production of thioviridamide and its derivatives, spores of Streptomyces avermitilis SUKA24 (4(saverm71-1286)::loxP $\quad \Delta$ (saverm2126-2167)::mloxP $\Delta\left(\right.$ saverm 2892-2903)::mut1-loxP $\quad \Delta\left(\right.$ saverm2990-3002) $:$ hph $\quad \Delta\left(\right.$ saverm7456-7491)::mut1-loxP $\quad$ SAP1 ${ }^{-} \quad$ SAP2 $\left.^{-}\right)$ carrying the biosynthetic gene cluster for each derivative were inoculated into a 50-ml test tube containing $10 \mathrm{ml}$ of vegetative medium ${ }^{2}$ and was grown with reciprocal shaking at $28^{\circ} \mathrm{C}$ for 2 days. A $0.1-\mathrm{ml}$ portion of the vegetative culture was used to inoculate a $125-\mathrm{ml}$ flask containing $10 \mathrm{ml}$ of production medium. ${ }^{3}$ The fermentation culture was carried out rotary shaker at $28^{\circ} \mathrm{C}$ for 5 days with $200 \mathrm{rpm}$. Large scale preparations of products were carried out baffled 500-ml flask containing $100 \mathrm{ml}$ of production medium.

\section{Experimental procedures}

\section{Construction of gene cluster carrying amino acid substitution in a gene encoding precursor peptide}

As previously reported, the biosynthetic gene clusters for thioviridamide (TVA) of $S$. olivovilidis $^{3}$ and neothioviridamide of Streptomyces sp. MSB090213SC12 ${ }^{4}$ were cloned into the integrating vectors pKU503 ${ }^{1}$ and pKU592Aaac(3)IV, respectively. Since the biosynthetic gene cluster for TVA was cloned as a part of pKU503thvP3-F8 (insert size: 71,900 bp), the minimized biosynthetic gene cluster for TVA was cloned by in vivo cloning using $\lambda$ RED system ${ }^{5}$. Both upstream and downstream regions flanking the biosynthetic genes for TVA were amplified by PCR with pKU503thvP3-F8 as template DNA using a primer pair of upstream, forward: 5'-ctcgagactagtGCTCCGAGGTCCTGGTGAAGGA-3' (underlined characters indicate SpeI site and uppercase characters indicate the upstream region of the gene cluster for TVA) and reverse: 5'-gaggatgtacatcGACGGGGTGCTGAGGTTCAGGT-3' (underlined characters indicate BsrGI site and uppercase characters indicate the upstream region of the gene cluster for TVA), and a primer pair of downstream, forward: 5'-aggatgtacaCAACGGTTGGTTCGTACGCTCCTC-3' (underlined characters indicate BsrGI site and uppercase characters indicate the downstream region of the gene cluster for TVA) and reverse: 5'-ctcgagaagcttCGCCTCACTGCCTTCCCGTACTT-3' (underlined characters indicate HindIII site and uppercase characters indicate the downstream region of the gene cluster for TVA). The initial denaturation step $\left(96^{\circ} \mathrm{C}\right.$ for 3 min) was followed by 25 cycles of amplification $\left(96^{\circ} \mathrm{C}\right.$ for $30 \mathrm{sec}, 50^{\circ} \mathrm{C}$ for $30 \mathrm{sec}$, and $72^{\circ} \mathrm{C}$ for $17 \mathrm{sec}$ ) and a final incubation at $72^{\circ} \mathrm{C}$ (5 min) using Expand High Fidelity DNA polymerase (Roche Diagnostics K.K., Tokyo, Japan). Cloning vector pRED was amplified by PCR with pRED::sacB::aph(3') as a template DNA using a primer pair of forward: 5'-ctcgagactagtTGCCAGGAAGATACTTAACAG-3' (underlined characters indicate SpeI site and uppercase characters indicate the region of pRED), and reverse: 5'-ctcgagaagcttCCATTCATCCGCTTATTATC-3' (underlined characters indicate HindIII site and uppercase characters indicate the region of pRED). The initial denaturation step $\left(96^{\circ} \mathrm{C}\right.$ for $\left.3 \mathrm{~min}\right)$ was followed by 25 cycles of amplification $\left(96^{\circ} \mathrm{C}\right.$ for $30 \mathrm{sec}, 50^{\circ} \mathrm{C}$ for $30 \mathrm{sec}$, and $72^{\circ} \mathrm{C}$ for $\left.98 \mathrm{sec}\right)$ and a final incubation at $72^{\circ} \mathrm{C}(5 \mathrm{~min})$ using Expand High Fidelity DNA polymerase. The 
amplicons of upstream (274-bp), downstream (265-bp) and pRED vector (1,631-bp) were digested with SpeI/BsrGI/DpnI, BsrGI/HindIII/DpnI and SpeI/HindIII/DpnI, respectively (DpnI was used for the degradation of the trace amount of template DNA). Both amplicons of upstream and downstream were ligated with amplicon of pRED vector by T4 DNA ligase at $12^{\circ} \mathrm{C}$ overnight. Ligation product was introduced into E. coli $\mathrm{DH} 5 \alpha$ by electroporation. Transformants were selected by LA containing $30 \mu \mathrm{g} / \mathrm{ml}$ of chloramphenicol. The recombinant plasmid was digested with $B s a \mathrm{BI}$ to generate linear molecules. The linearized molecules and XhoI-digested pKU503thvP3-F8 were co-transformed into L-arabinose-induced E. coli BW25141 / pKD119 (obtained from The Coli Genetic Stock Center; http://cgsc2.biology.yale.edu/) by electroporation. Transformants were selected by LA containing $30 \mu \mathrm{g} / \mathrm{ml}$ of chloramphenicol. The desired clones were confirmed by restriction digestion. The resulting clone, pRED::tva cluster, was digested with SpeI and HindIII and the largest fragment containing the entire biosynthetic gene cluster for TVA was ligated with the largest fragment of XbaI/HindIII-digested pKU592Aaac(3)IV. Transformants were selected by LA containing $25 \mu \mathrm{g} / \mathrm{ml}$ of apramycin. The desired clones (pKU592Aaac(3)IV::tva cluster; accession number: LC466032) were confirmed by restriction digestion. The minimized biosynthetic gene cluster for neothioviridamide ( $n t v$ cluster) of Streptomyces sp. MSB090213SC12 (pKU592Aaac(3)IV::ntv cluster; accession number: LC466033) was also obtained by the same protocol. To prepare both upstream and downstream amplicons, following primer pairs were used: primer pairs of upstream, forward: 5'-ctcgagactagtCAGTTCGACGCTGGACAGGAAGG-3' (underlined characters indicate SpeI site and uppercase characters indicate the upstream region of the gene cluster for neothioviridamide), and reverse: 5'-ctcgagtgtacaGAATAGATTGGGGGCAGGGACGAG-3' (underlined characters indicate BsrGI site and uppercase characters indicate the upstream region of the gene cluster for neothioviridamide), and downstream, forward: 5'-ctcgagtgtacaGGAGCCCTTGGATGCTCTCTCCTC-3' (underlined characters indicate HindIII site and uppercase characters indicate the downstream region of the gene cluster for neothioviridamide), and reverse: 5'-ctcgagaagcttCCCAGCAAGACCATCGTGTACCAA-3' (underlined characters indicate HindIII site and uppercase characters indicate the downstream region of the gene cluster for neothioviridamide). Replacement of gene (tvaA or $n t v A$ ) encoding the precursor peptide into the resistance marker were carried out via $\lambda$ RED system. In order to prepare the tvaA-disruption cassette, the resistance marker, aph(3'), flanking with 50-bp of upstream and downstream regions of the target gene was amplified by PCR with pKU479 ${ }^{6}$ as template DNA using a primer pair of the resistance marker region, forward: 5' '-gcgacgtctcggaggtcccgagggtcgaagtgtgaagggaacgagtcatggtatacCTTCATGAGCTCAGCCAATC-3' (lowercase characters indicate the upstream region of $t v a A$, underlined characters indicate BstZ17I site, and uppercase characters indicate the region of the marker gene) and reverse: 5'-ccgggetctccggtccccaccggatgcccagcgtccetgcccagtgcctggtatacTGCCGTATTTGCAGTACCAG-3' (lowercase characters indicate the downstream region of $t v a A$, underlined characters indicate BstZ17I site, and uppercase characters indicate the region of the marker gene). The ntvA-disruption cassette was prepared similarly using a primer pair of the resistance marker region, forward: 5' -gtccattcgattccccagccaactggcaggggacgaattaggaggatcaagtatacTGCCGTATTTGCAGTACCAG-3' (lowercase 
characters indicate the upstream region of $n t v A$, underlined characters indicate BstZ17I site, and uppercase characters indicate the region of the marker gene) and reverse: 5' -tgccggtcgggetgtgcgaagcgetggtcatcatgaggtgaacgectcagagtatacCTTCATGAGCTCAGCCAATC-3' (lowercase characters indicate the downstream region of $n t v A$, underlined characters indicate BstZ17I site, and uppercase characters indicate the region of the marker gene). The initial denaturation step $\left(96^{\circ} \mathrm{C}\right.$ for 3 min) was followed by 5 cycles of amplification $\left(96^{\circ} \mathrm{C}\right.$ for $30 \mathrm{sec}, 50^{\circ} \mathrm{C}$ for $30 \mathrm{sec}$, and $72^{\circ} \mathrm{C}$ for $\left.90 \mathrm{sec}\right), 25 \mathrm{cycles}$ of amplification $\left(96^{\circ} \mathrm{C}\right.$ for $30 \mathrm{sec}$ and $68^{\circ} \mathrm{C}$ for $\left.90 \mathrm{sec}\right)$, and a final incubation at $72^{\circ} \mathrm{C}(5 \mathrm{~min})$ using Expand High Fidelity DNA polymerase. After the amplification of each segment, 5 units of $D p n I$ were added to remove the trace amount of template DNA and amplified segments were purified by the glass bead-binding method using the GENECLEAN Kit (Funakoshi Co., Ltd, Tokyo, Japan). The resulting amplicons and pKU592Aaac(3)IV::tva cluster or pKU592Aaac(3)IV::ntv cluster were co-transformed into L-arabinose-induced E. coli BW25141 / pKD119 by electroporation. Transformants were selected by LA containing $50 \mu \mathrm{g} / \mathrm{ml}$ of kanamycin and $25 \mu \mathrm{g} / \mathrm{ml}$ of apramycin. The desired clones (pKU592Aaac(3)IV::tva cluster $\Delta t v a A:: a p h\left(3^{\prime}\right)$ and pKU592Aaac(3)IV::ntv cluster $\Delta n t v A:: a p h\left(3^{\prime}\right)$ ) were confirmed by restriction digestion.

The synthetic genes (tvaA; 360-bp and $n t v A ; 456-\mathrm{bp})$ encoding precursor peptides for TVA and neothioviridamide with two silent mutations at 5', and 3' region of the core peptide coding sequence, respectively, were obtained from Eurofins Genomics, Tokyo, Japan. The EcoRI/HindIII fragment of each gene encoding precursor peptide (tvaAsyn; accession number: LC466034 and ntvAsyn; accession number: LC466035) was cloned into EcoRI/HindIII-large fragment of pRED::aac(3)I by T4 DNA ligase. Ligation product was introduced into E. coli DH5 $\alpha$ by electroporation and transformants were selected by LA containing $10 \mu \mathrm{g} / \mathrm{ml}$ of gentamicin.

The designed precursor peptide gene was prepared by ligating the large fragment of BamHI/NheI-digested pRED::tvaAsyn or pRED::ntvAsyn (prepared by PCR amplification using pRED::tvaAsyn or pRED::ntvAsyn as template DNA using primer pairs, forward: 5'-TTCACTGCTAGCAGGCACTGGGCAGGGACGC-3', reverse: 5'-TTCACTGCTAGCAGGCACTGGGCAGGGACGC-3') for designed tvaA or forward: 5'-GGCCTTCCACTGCTAGCCTGAGGCGTTCACCTCATG-3', reverse: 5'-CATCACGGATCCCTGCGCCTCCTCGTCGGG-3' for designed $n t v A$, respectively) with a short dsDNA fragment encoding the core peptide region. The short dsDNA fragments were prepared by annealing of a pair of complemental 40-mer oligonucleotides (Table S3). The recombinant designed genes were amplified by PCR with pRED::tvaA_X\#Y and pRED::ntvA_X\#Y using primer pair of the flanking region, forward: 5'-TTAAGTATCTTCCTGGCAGAATtC-3' and reverse: 5'-TAATAAGCGGATGAATGGAAGCTT-3'. After the resulting amplicon were digested with EcoRI, HindIII and DpnI (removal of template DNA), digested each amplicon and large fragment of BstZ17I-digested pKU592Aaac(3)IV::tva cluster $\Delta t v a A:: a p h\left(3^{\prime}\right)$ or pKU592Aaac(3)IV::ntv cluster $\triangle n t v A:: a p h\left(3^{\prime}\right)$ were assembled by Gibson's assembly. ${ }^{7}$ Assembled circular plasmids were introduced into E. coli DH5 $\alpha$. Desired transformants were selected by apramycin-resistance $(25$ $\mu \mathrm{g} / \mathrm{ml}$ ) and kanamycin-sensitivite phenotype. The desired clones (pKU592Aaac(3)IV::tva cluster $\triangle t v a A:: t v a A \_X \# Y$ and pKU592Aaac(3)IV::ntv cluster $\left.\Delta n t v A:: n t v A \_\mathrm{X} \# \mathrm{Y}\right)$ were confirmed by restriction digestion. The resultant 
recombinant plasmids were introduced into E. coli GM2929 hsdS::Tn10 to prepare unmethylated DNA. The unmethylated DNA preparations were transformed into S. avermitilis SUKA22 by polyethylene glycol-assisted protoplast transformation as described previously ${ }^{4}$

\section{Isolation of TVA-like compounds}

The fermentation broth was centrifuged, and the collected mycelial cake was extracted with methanol. After concentration of methanol extract in vacuo, the residual aqueous concentrate was partitioned between ethyl acetate and water. The ethyl acetate-soluble material was subjected to silica gel MPLC eluted with an isocratic mode with $n$-hexane:ethyl acetate $=3: 1$ followed by an isocratic mode with chloroform:methanol:ammonium hydroxide $=$ 50:10:1 or 2. Fractions were monitored using the UPLC-ESI-MS system. The fractions containing the desired compound were combined, neutralized, and concentrated in vacuo. The crude extract was purified by reserved-phase HPLC on a $\mathrm{C}_{18}$ column, using an isocratic mode with $50 \%, 55 \%$ or $60 \%$ acetonitrile-50 $\mathrm{mM}$ ammonium formate. The yields of each compound are summarized in Table S1 and S2.

\section{Cytotoxicity assay}

The cytotoxic activities of 20 derivatives as well as prethioviridamide and neothioviridamide against human ovarian adenocarcinoma SKOV-3 cells, malignant pleural mesothelioma Meso-1 cells, and immortalized human T lymphocyte Jurkat cells were examined. SKOV-3 cells were cultured in DMEM medium supplemented with 10\% fetal bovine serum, penicillin $(50 \mathrm{U} / \mathrm{mL})$, and streptomycin $(50 \mu \mathrm{g} / \mathrm{mL})$. Meso-1 cells were cultured in RPMI1640 medium supplemented with $10 \%$ fetal bovine serum, penicillin $(50 \mathrm{U} / \mathrm{mL})$, and streptomycin $(50 \mu \mathrm{g} / \mathrm{mL})$. Jurkat cells were cultured in RPMI1640 medium supplemented with $10 \%$ fetal bovine serum, penicillin $(50 \mathrm{U} / \mathrm{mL})$, streptomycin $(50 \mu \mathrm{g} / \mathrm{mL})$, and Glutamax. All cell lines were seeded in a 384-well plate at a density of 1,000 cells/well in $20 \mu \mathrm{L}$ of media and incubated at $37^{\circ} \mathrm{C}$ in a humidified incubator with $5 \% \mathrm{CO}_{2}$. After $4 \mathrm{~h}, 2$-fold dilution samples were added to the cell culture at the concentration of $0.5 \%$ and incubated for $72 \mathrm{~h}$. Cell viabilities were measured using a CellTiter-Glo luminescent cell viability assay and EnVision multilabel plate reader. 


\section{Prethioviridamide series}

$$
\begin{aligned}
& \text { Prethioviridamide } \\
& \text { TVA_V11 } \\
& \text { TVA_M2L } \\
& \text { TVA_S7T } \\
& \text { TVA_I8L } \\
& \text { TVA_L10A } \\
& \text { TVA_H11T } \\
& \text { TVA_A4I-L10Y } \\
& \text { TVA_I8V-L10F } \\
& \text { TVA_A4I-S7T-L10Y } \\
& \text { TVA_S7T-18V-L10Y }
\end{aligned}
$$


By-products of prethioviridamide series

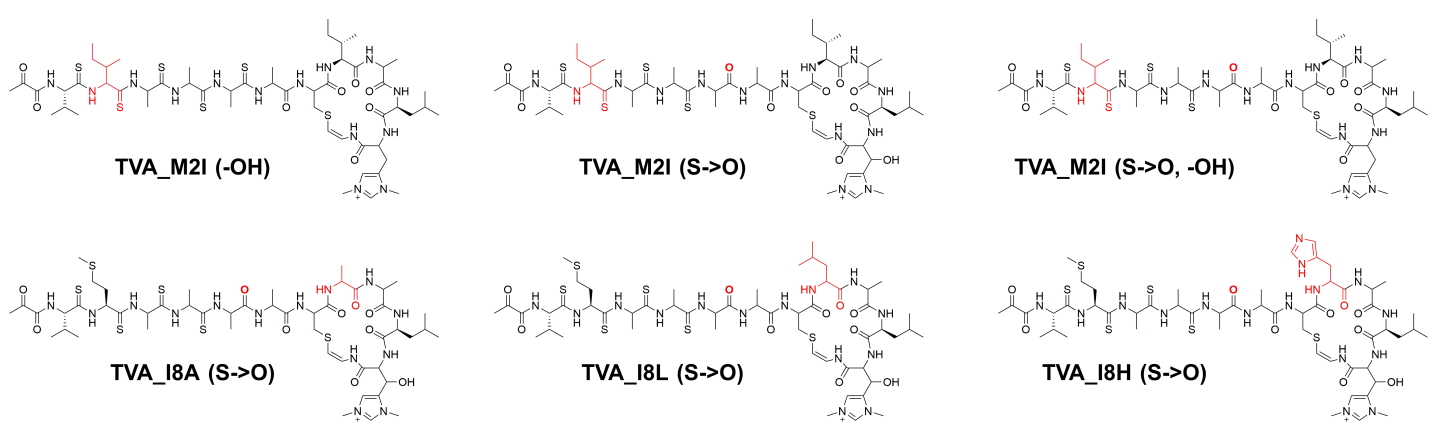

NTV series

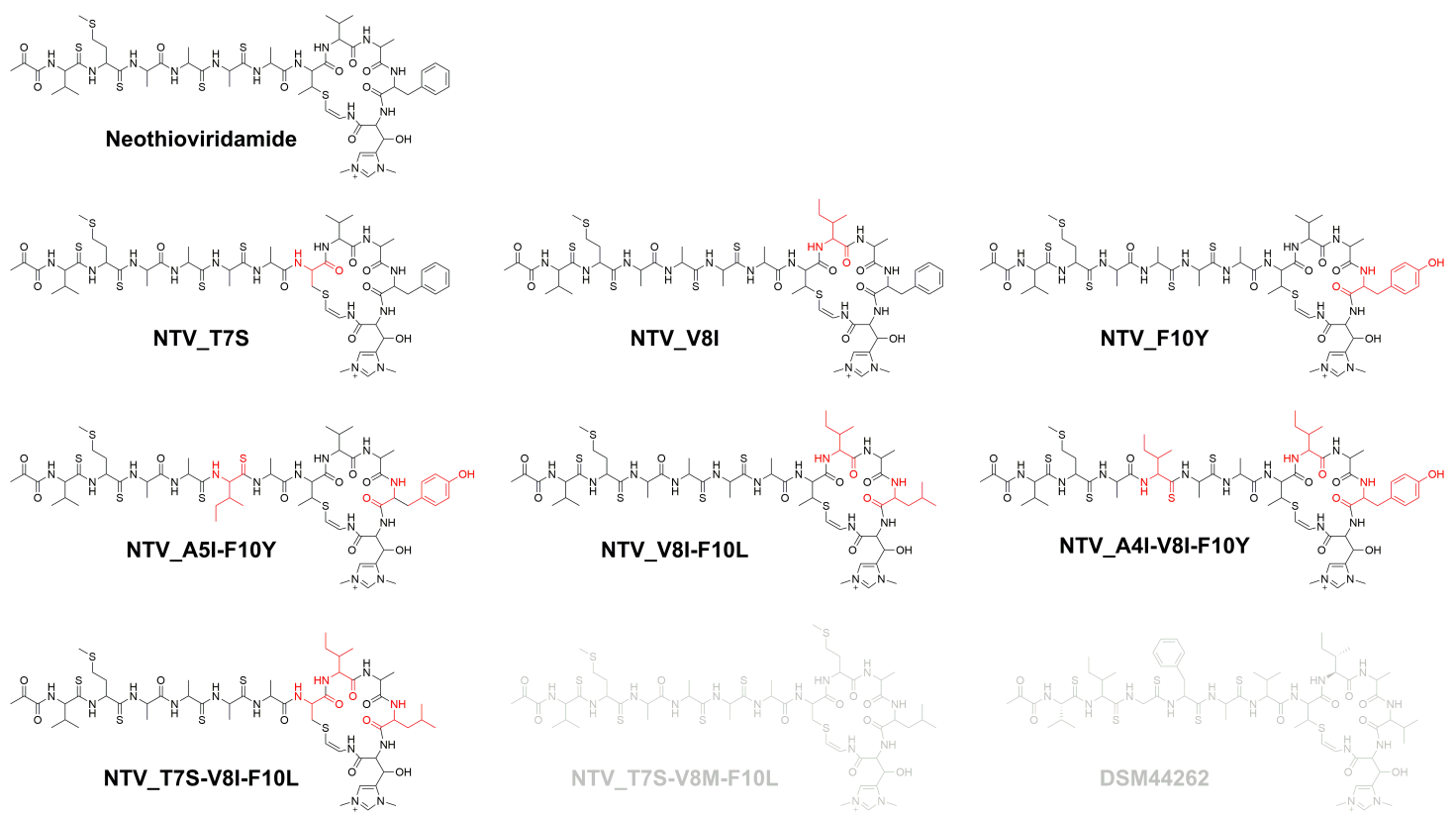

CNT029

By-products of NTV series

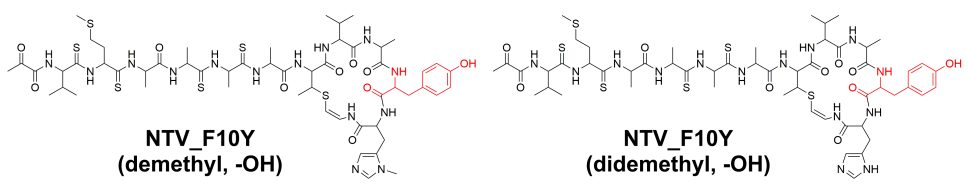

Figure S1. Designed derivatives and by-products. The substituted amino acids are colored in red. Those gave no detectable products are colored in gray. 


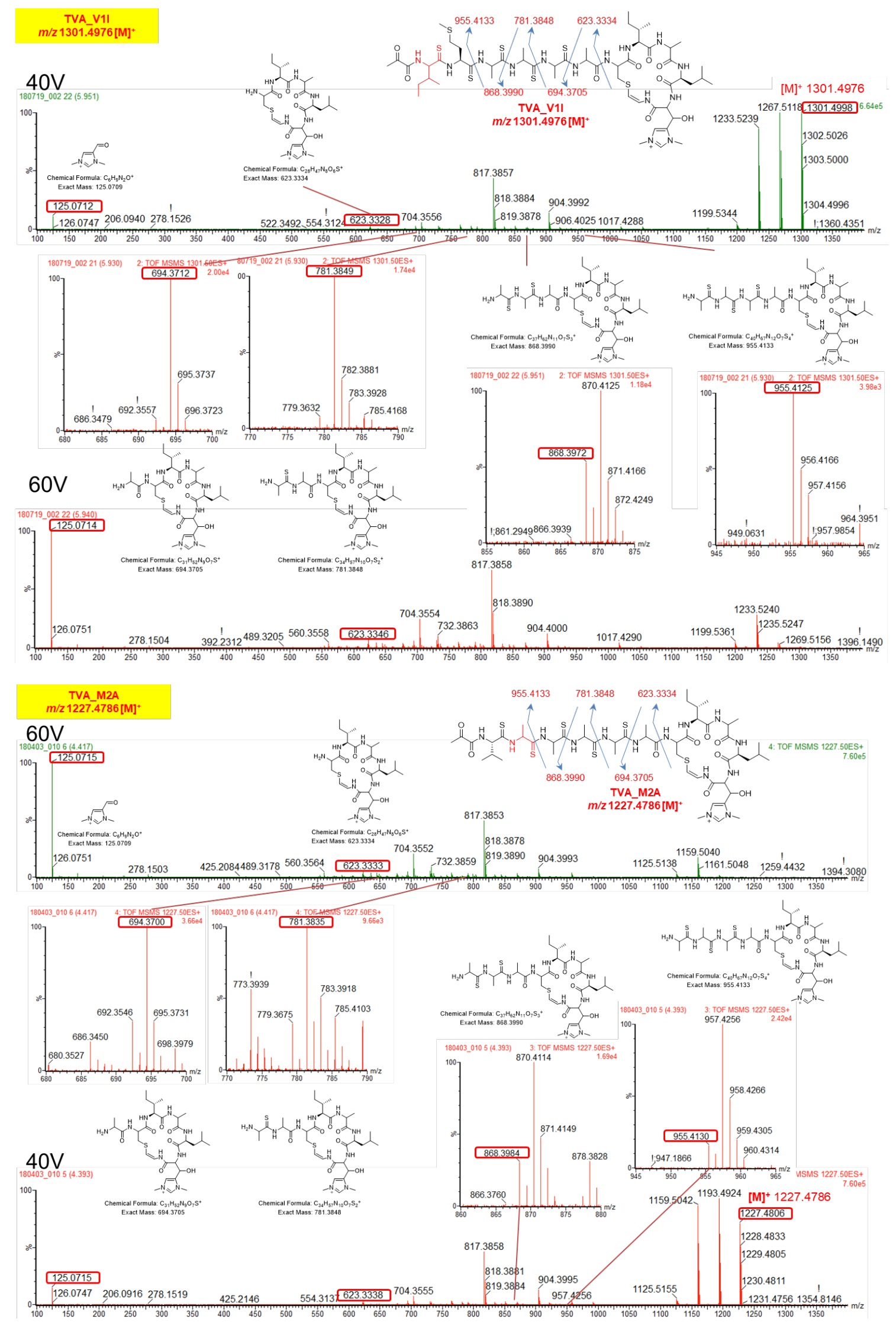




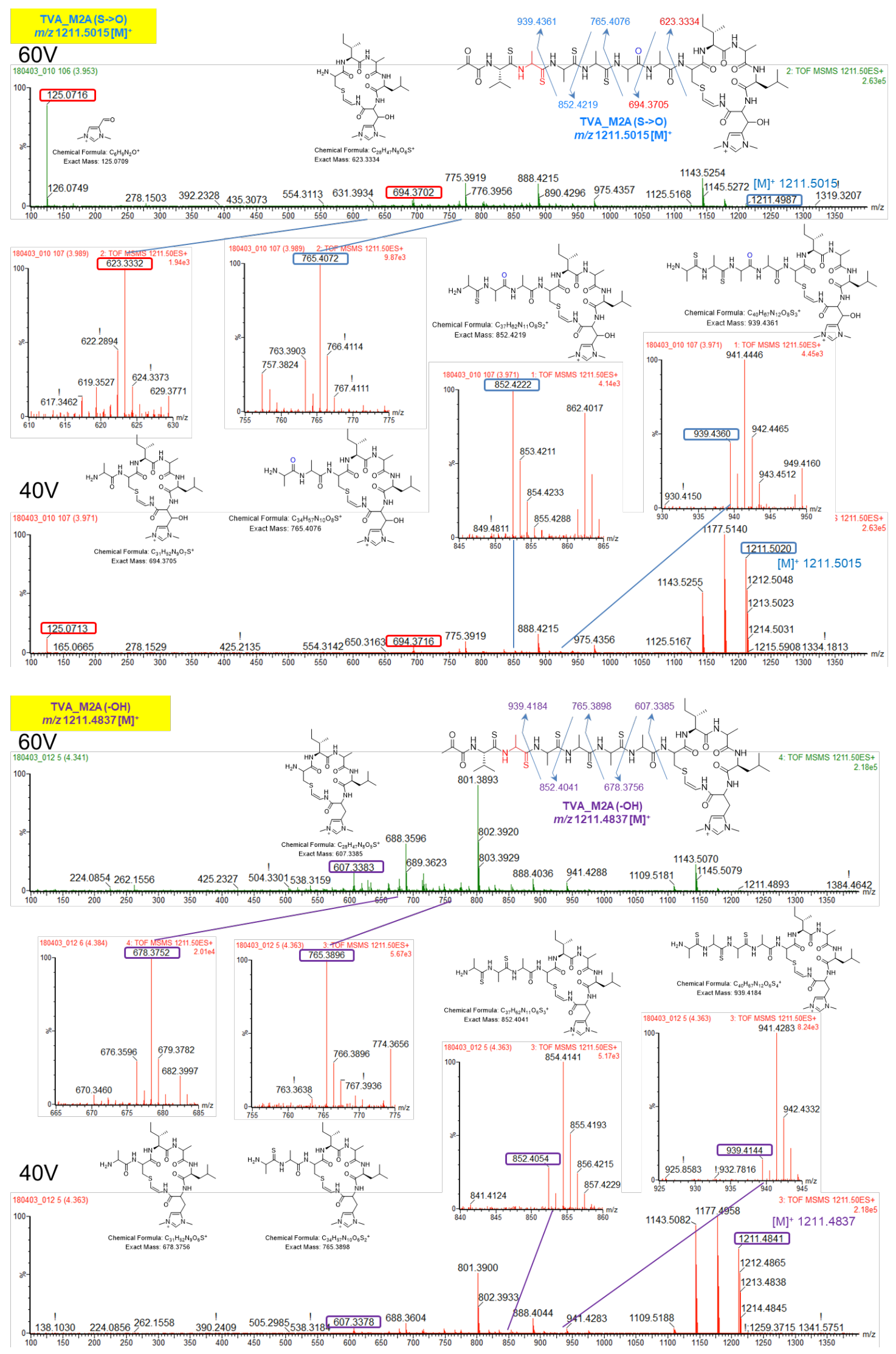



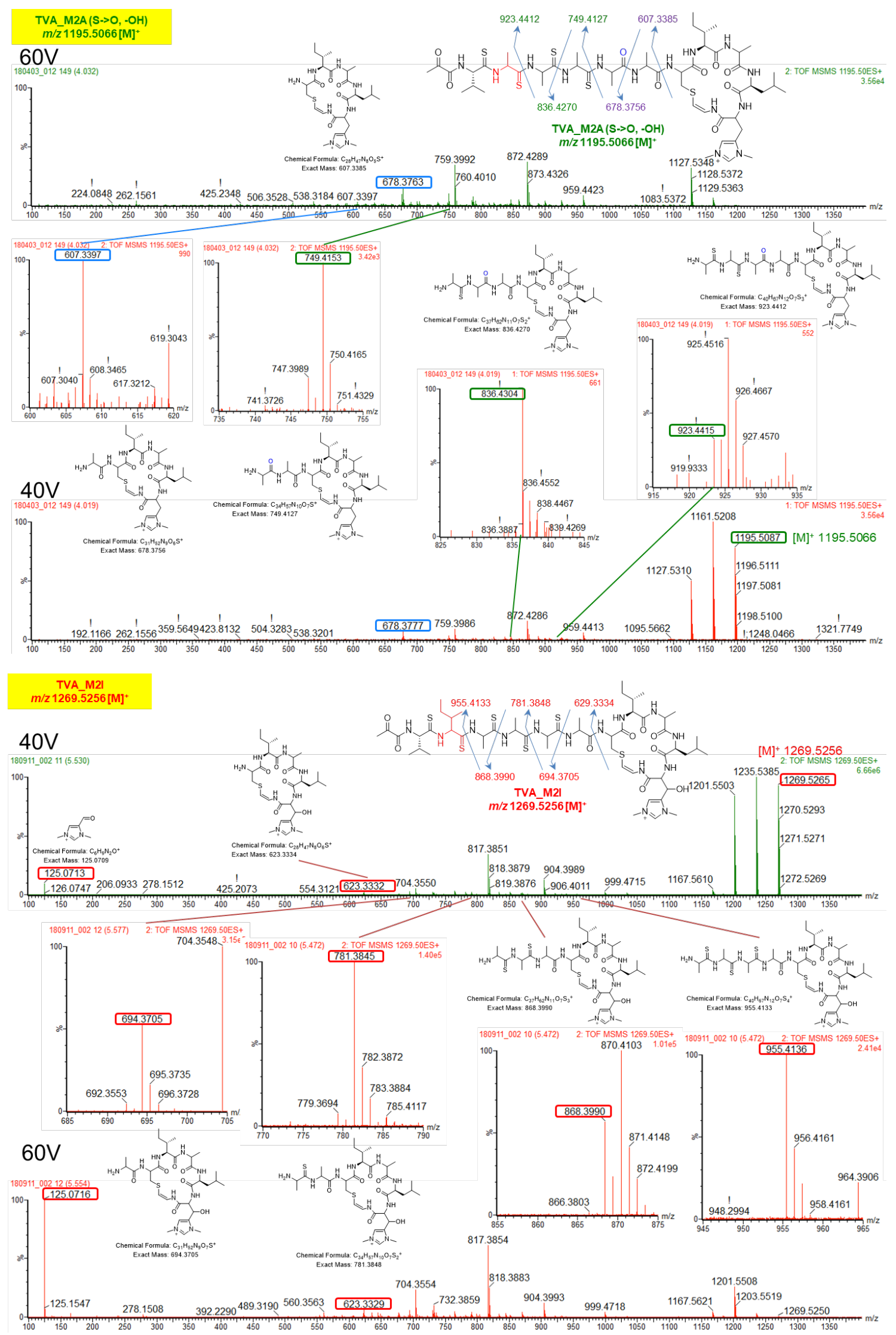


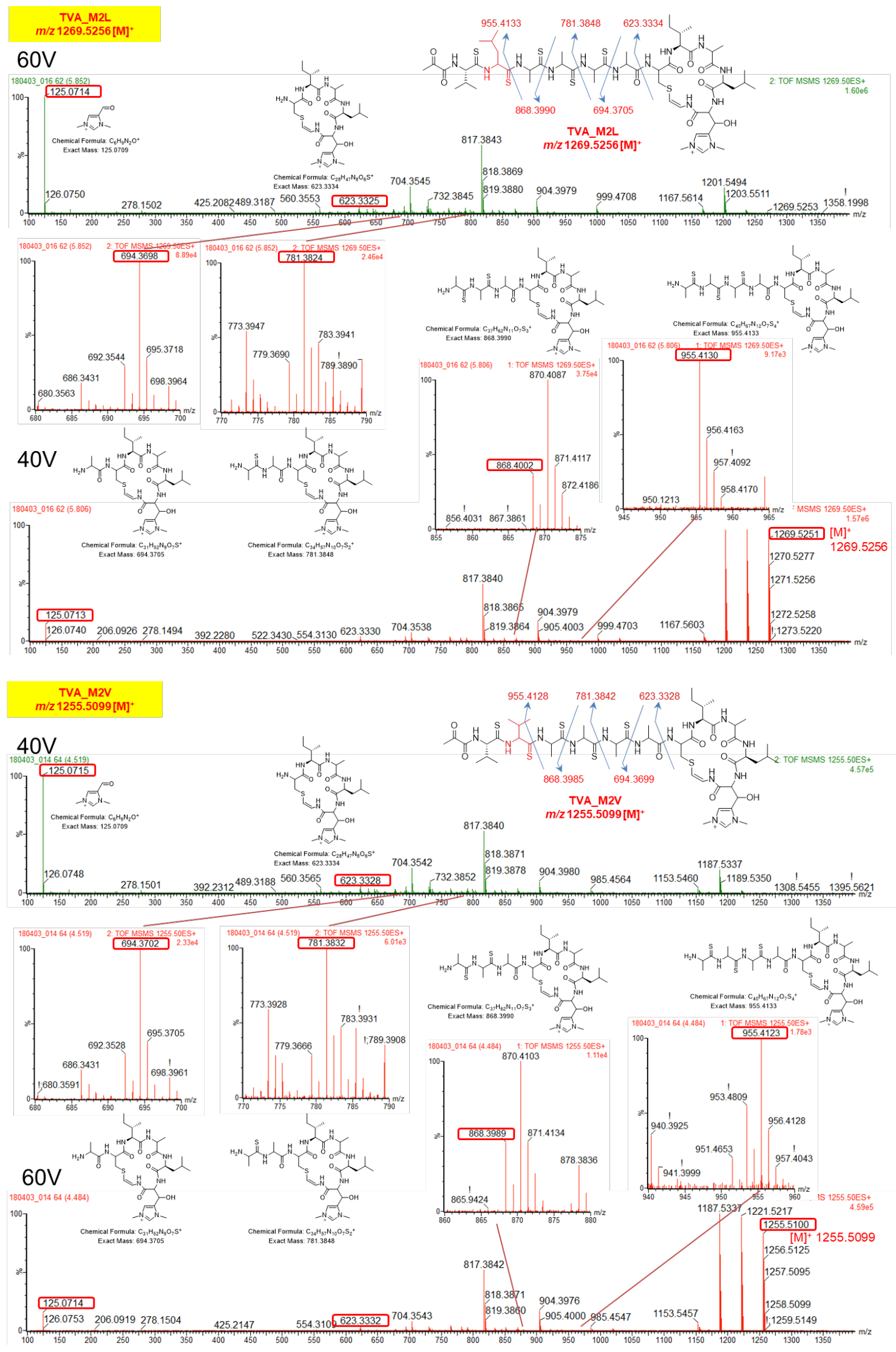




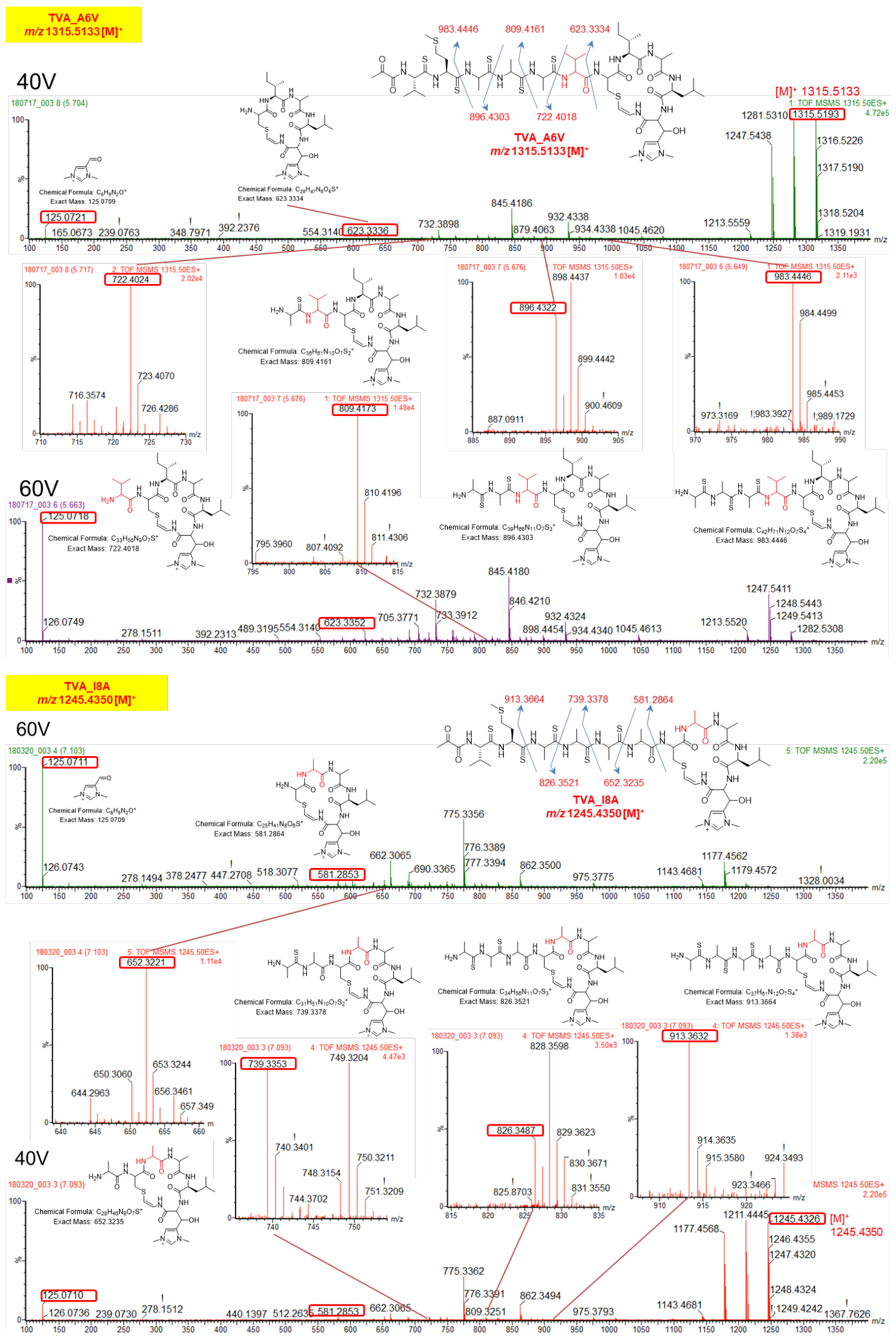




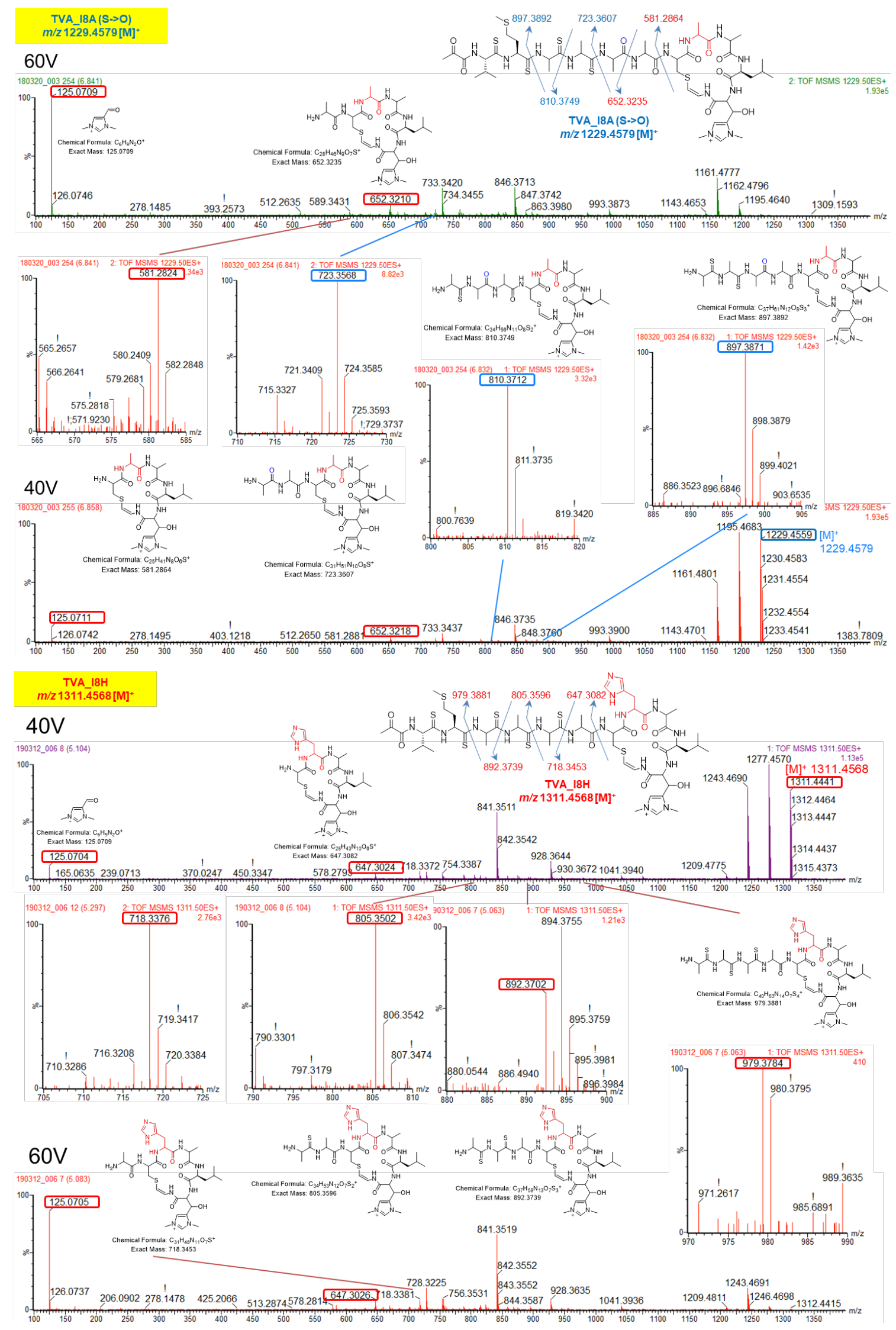




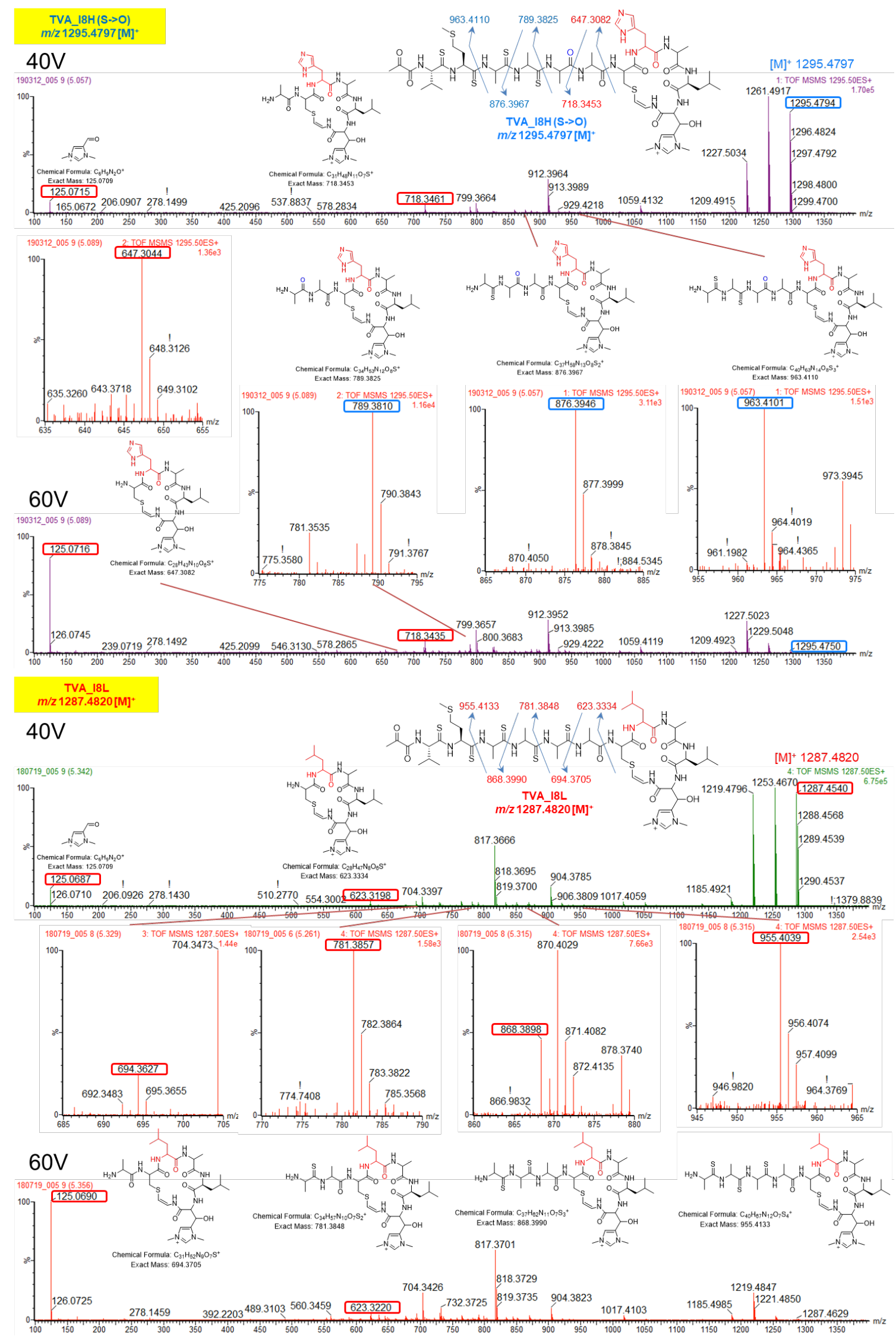




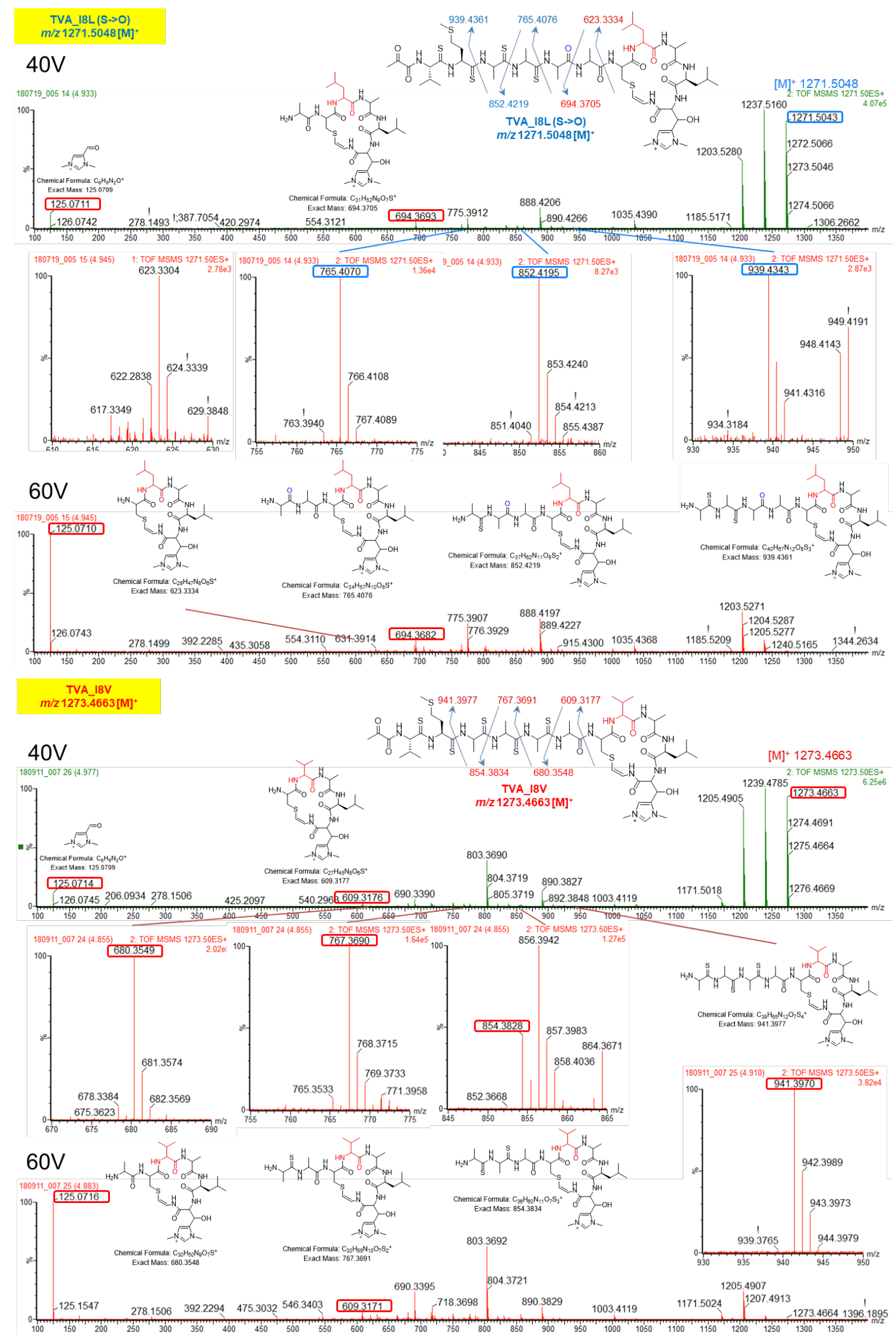




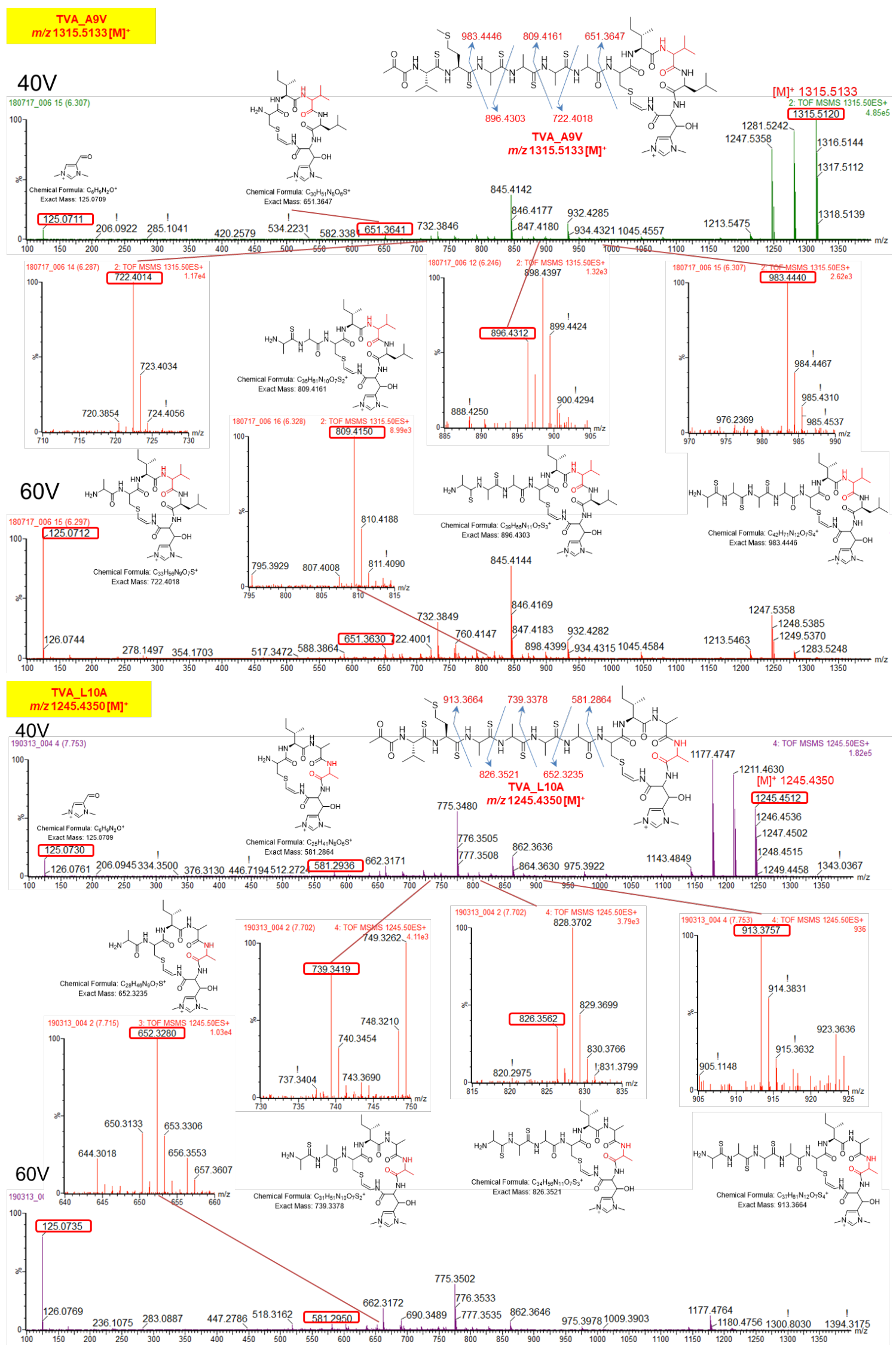




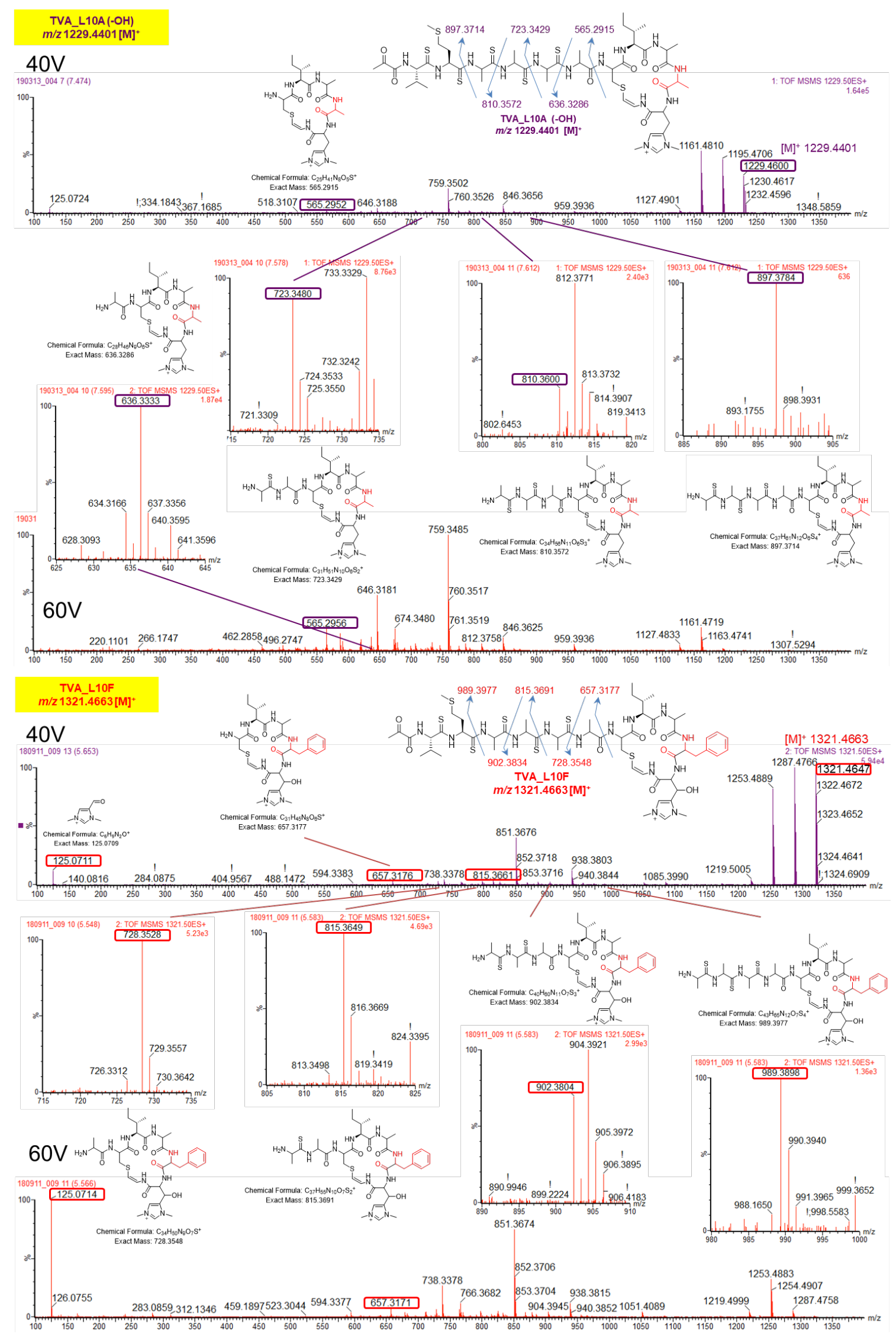




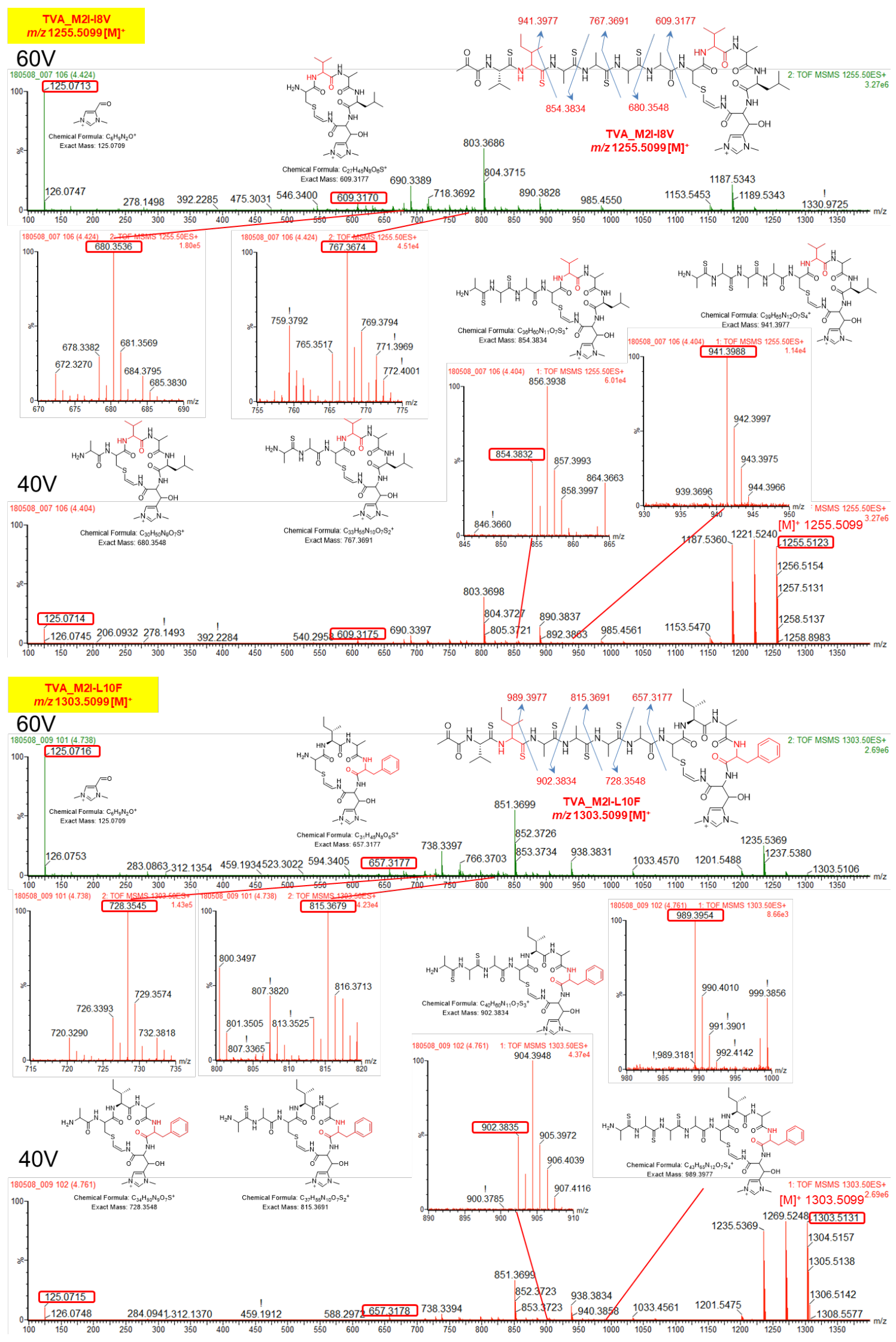




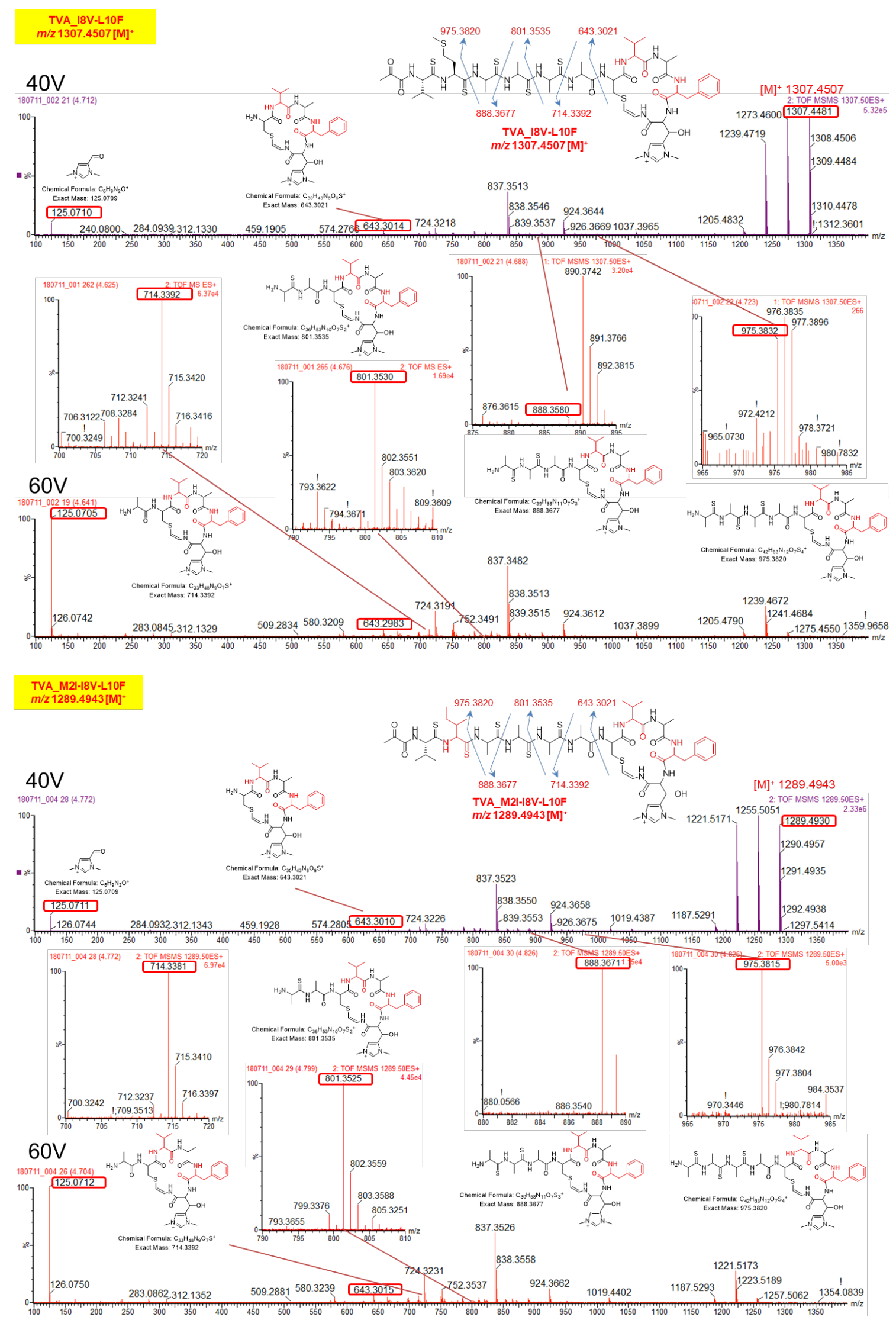




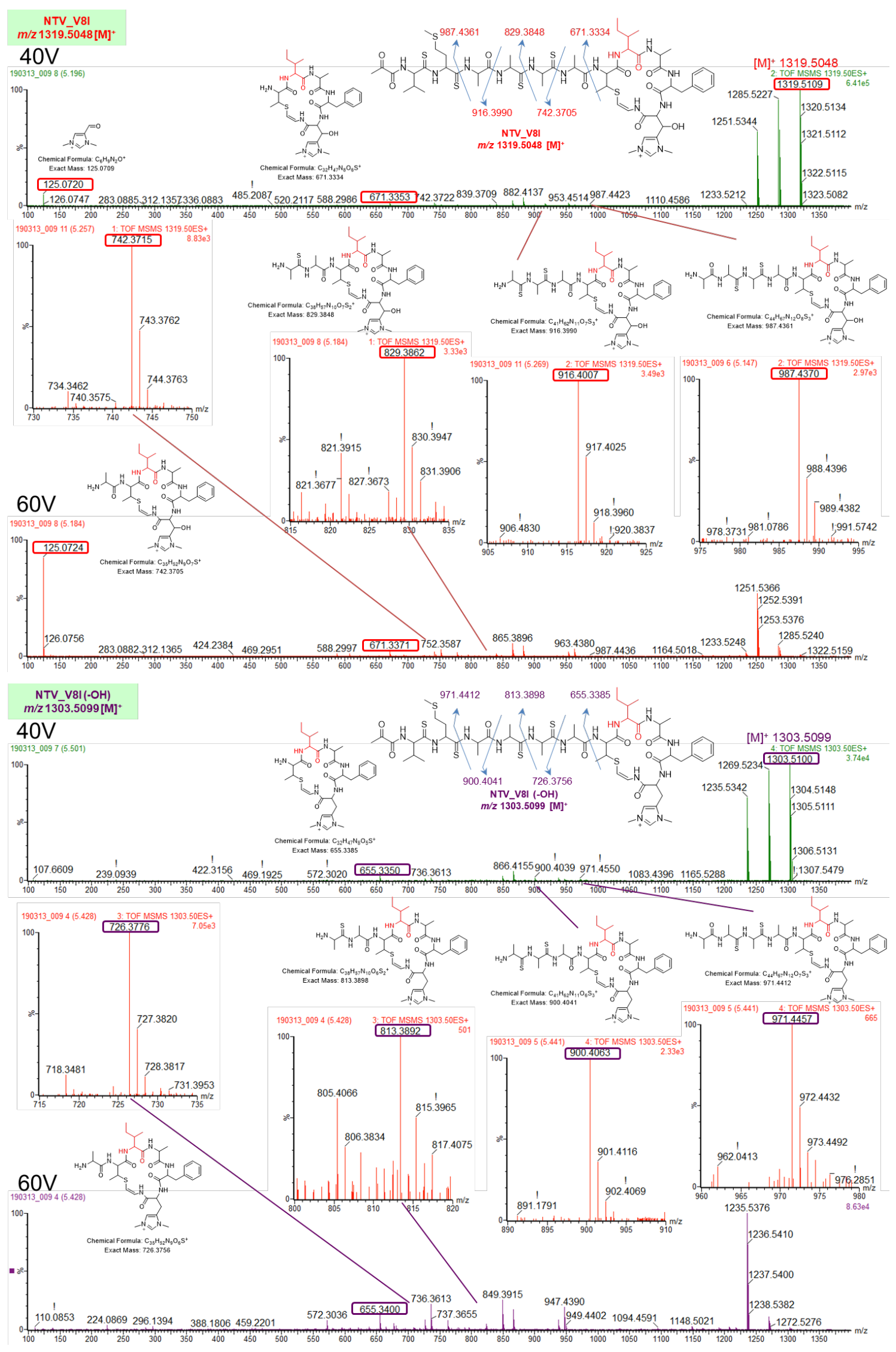




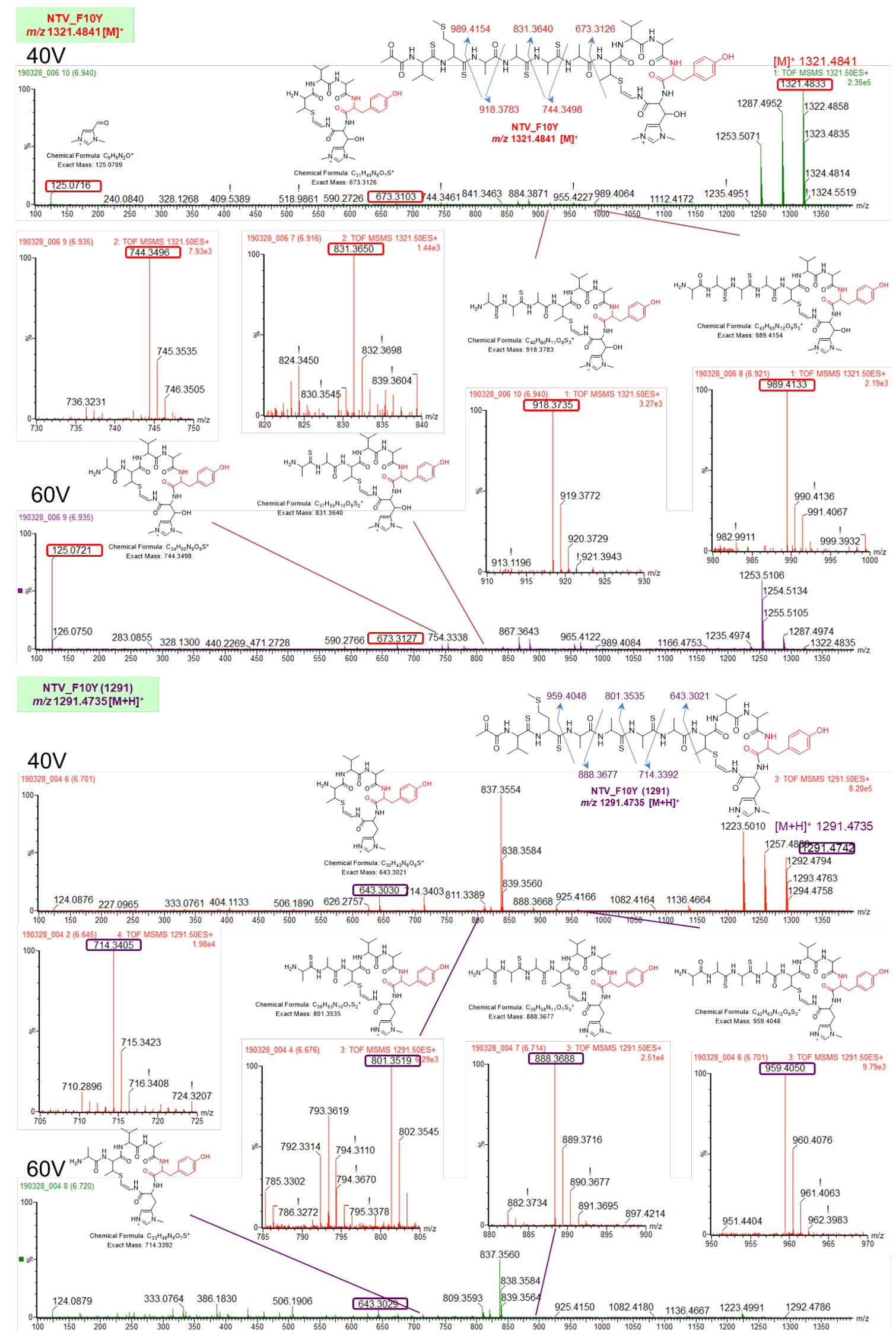




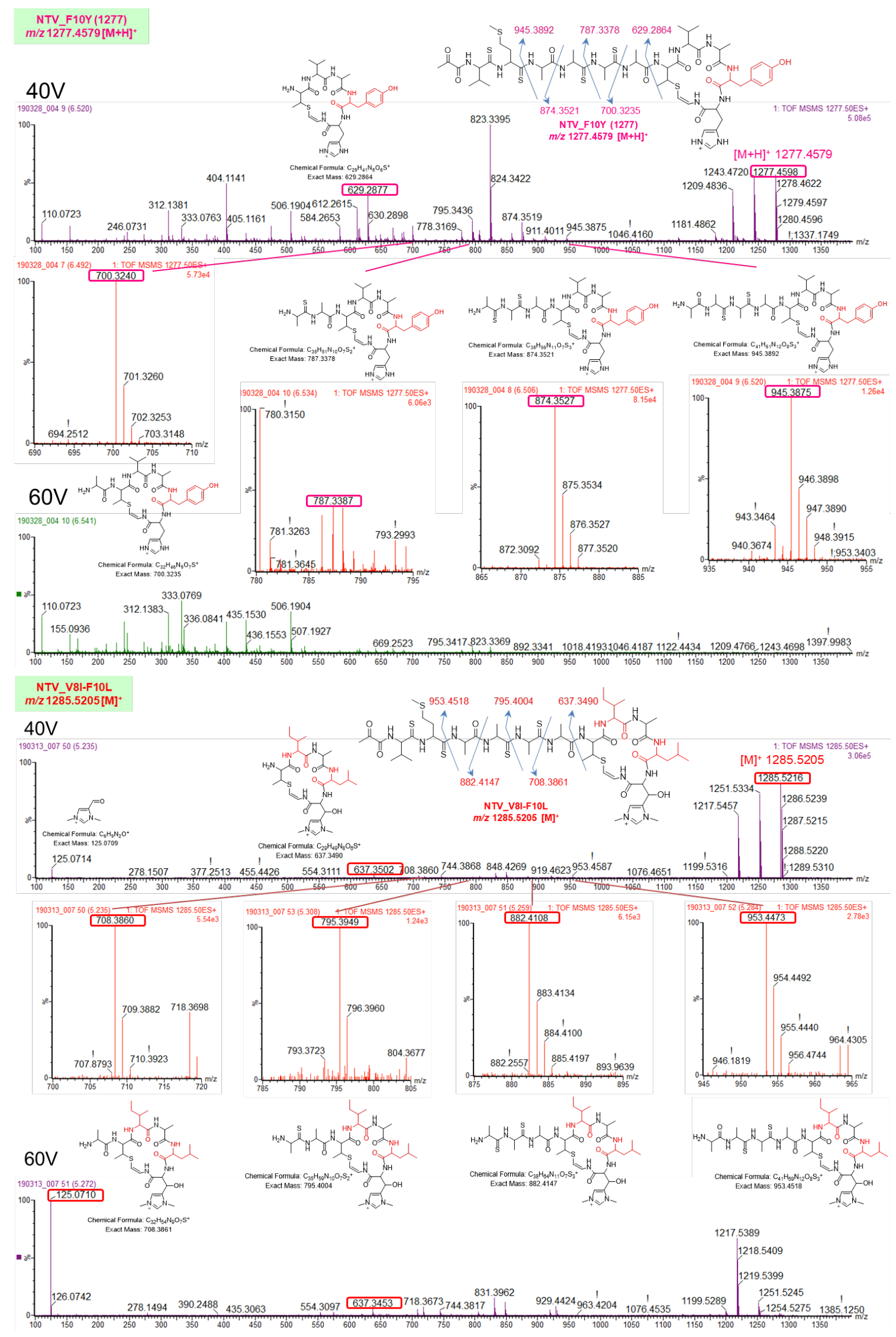


Figure S2. MS/MS analysis of the thioviridamide derivatives. The spectra of those subjected to the cytotoxicity assay and those produced with minor components are shown. Key mass peaks are boxed. Deduced fragmentation patterns and each structure of the fragment ions are indicated with their calculated monoisotopic mass. The productions of the other derivatives were confirmed by HRMS. 


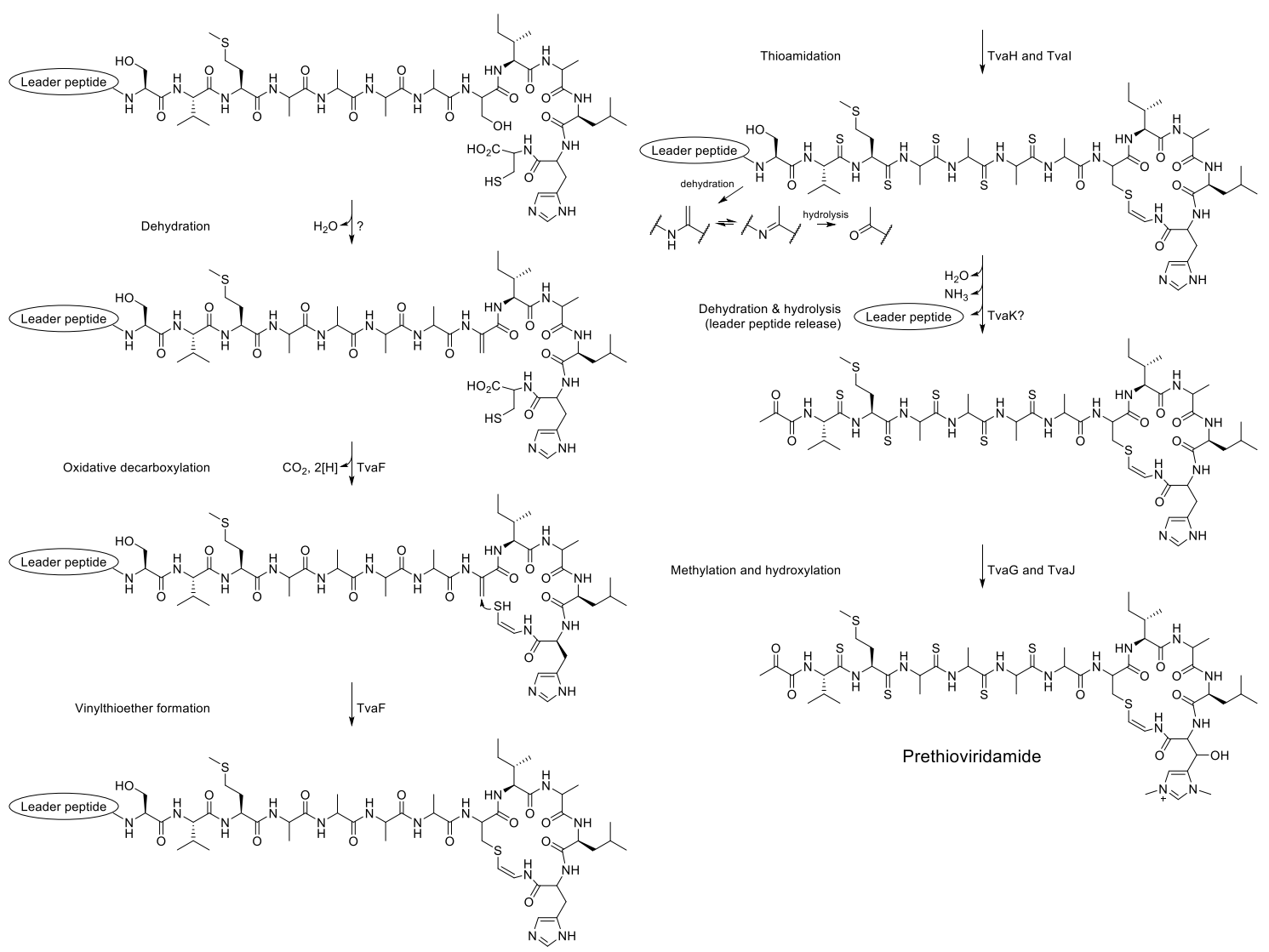

Figure S3. Proposed biosynthetic pathway for prethioviridamide 


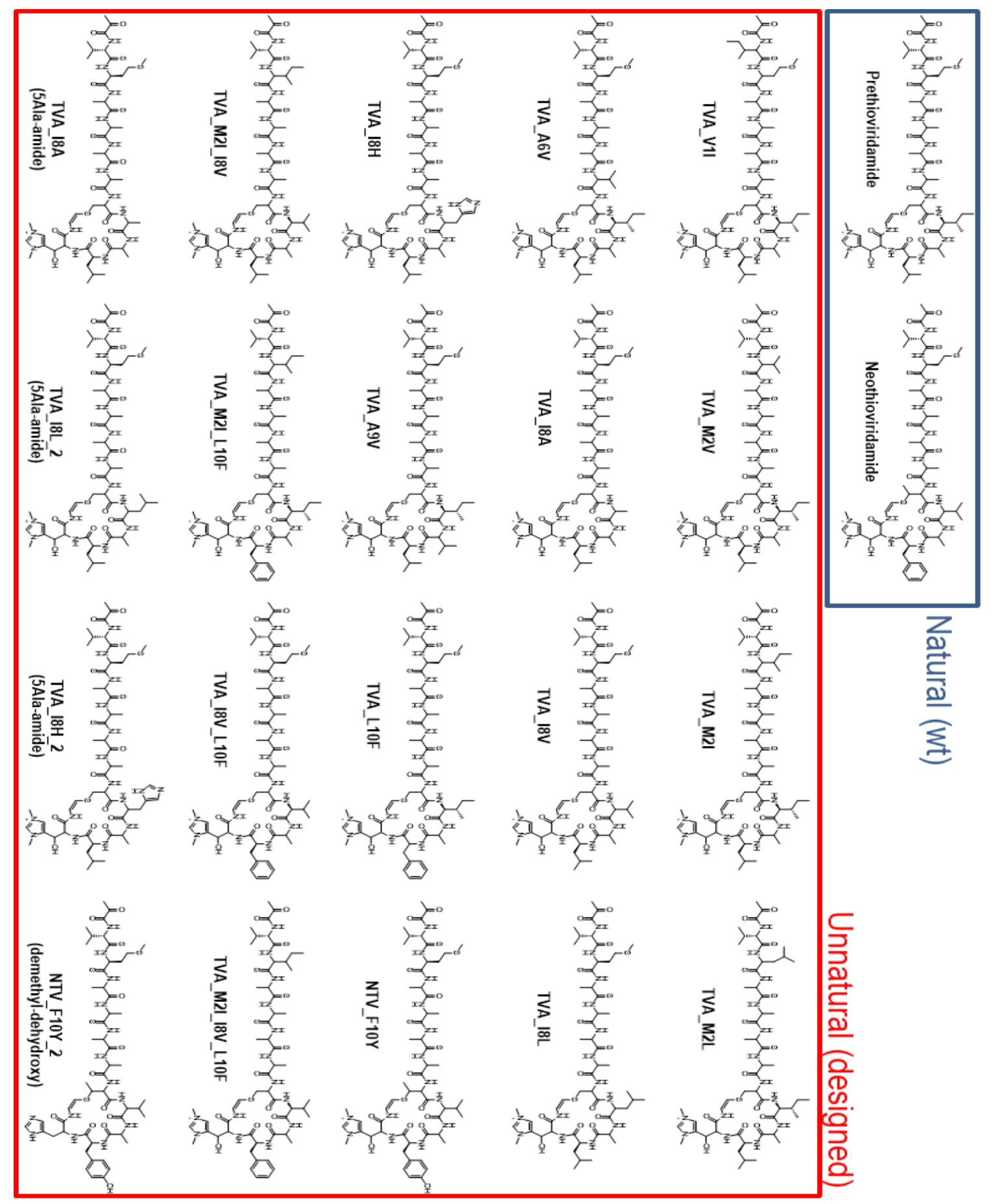

Figure S4. TVA derivatives subjected to cytotoxicity assay 
A
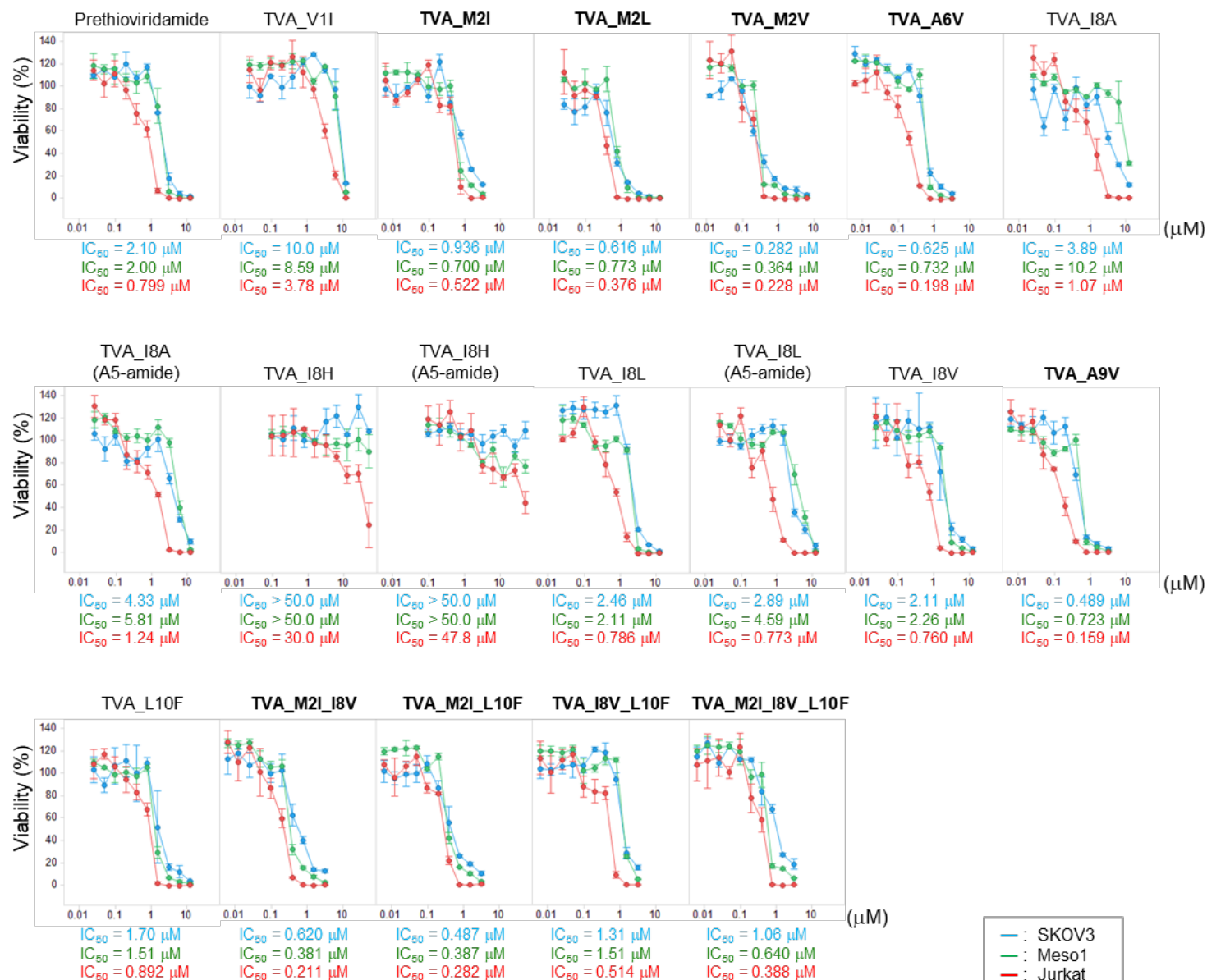

B

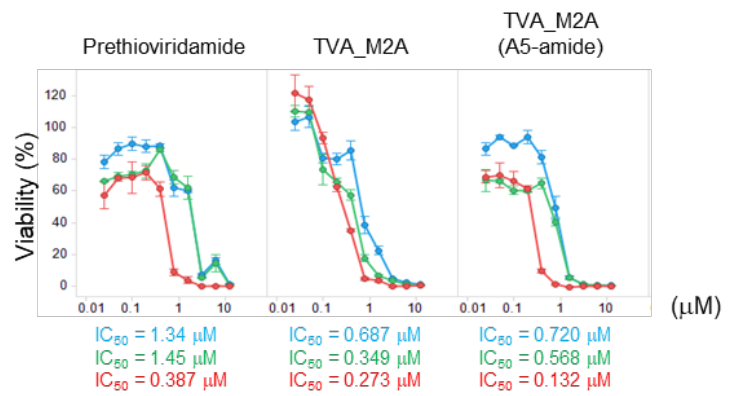

Figure S5. Viability of cells treated with TVA derivatives

The cytotoxic activity was significantly improved by the compounds written in bold letters. The results of panel A and panel B were obtained from separate experiments (absolute values are not to be compared). The potency of each compound is discussed in relation to the $\mathrm{IC}_{50}$ value of prethioviridamide of each experiment. 
Table S1. Primers used in this study

Prethioviridamide series

\begin{tabular}{|c|c|c|c|c|}
\hline No. & Designation & Strand & Primer sequence & Translated AA \\
\hline & Prethioviridamide & $5^{\prime}->3^{\prime}(+)$ & gatcCGTCATGGCCGCCGCTGCGTCGATCGCTCTTCACTGctag & VMAAAASIALHC \\
\hline 1 & V1I & $\begin{array}{l}5^{\prime}->3^{\prime}(+) \\
3^{\prime}<-5,(-)\end{array}$ & $\begin{array}{l}\text { gatcCATCATGGCCGCCGCTGCGTCGATCGCTCTTCACTG } \\
\text { GTAGTACCGGCGGCGACGCAGCTAGCGAGAAGTGACgatc }\end{array}$ & IMAAAAS IALHC \\
\hline 2 & $\mathrm{M} 2 \mathrm{~A}$ & $\begin{array}{l}5^{\prime}->3^{\prime}(+) \\
3^{\prime}<-5,(-)\end{array}$ & $\begin{array}{l}\text { gatcCGTCGCGGCCGCCGCTGCGTCGATCGCTCTTCACTG } \\
\text { GCAGCGCCGGCGGCGACGCAGCTAGCGAGAAGTGACgatc }\end{array}$ & VAAAAAS IALHC \\
\hline 3 & M2I & $\begin{array}{l}5^{\prime}->3{ }^{\prime}(+) \\
3{ }^{\prime}<-5 \\
\end{array}$ & $\begin{array}{l}\text { gatcCGTCATCGCCGCCGCTGCGTCGATCGCTCTTCACTG } \\
\text { GCAGTAGCGGCGGCGACGCAGCTAGCGAGAAGTGACgatc }\end{array}$ & VIAAAAS IALHC \\
\hline 4 & $\mathrm{M} 2 \mathrm{~L}$ & $\begin{array}{l}5,->3,(+) \\
3^{\prime}<-5,(-)\end{array}$ & $\begin{array}{l}\text { gatcCGTCCTCGCCGCCGCTGCGTCGATCGCTCTTCACTG } \\
\text { GCAGGAGCGGCGGCGACGCAGCTAGCGAGAAGTGACgatc }\end{array}$ & VLAAAAS IALHC \\
\hline 5 & $\mathrm{M} 2 \mathrm{~V}$ & $\begin{array}{l}5^{\prime}->33^{\prime}(+) \\
3^{\prime}<-5,(-)\end{array}$ & $\begin{array}{l}\text { gatcCGTCGTCGCCGCCGCTGCGTCGATCGCTCTTCACTG } \\
\text { GCAGCAGCGGCGGCGACGCAGCTAGCGAGAAGTGACgatc }\end{array}$ & VVAAAASIALHC \\
\hline 6 & $\mathrm{~A} 6 \mathrm{~V}$ & $\begin{array}{l}5^{\prime}->3,(+) \\
3^{\prime}<-5,(-)\end{array}$ & $\begin{array}{l}\text { gatcCGTCATGGCCGCCGCTGTGTCGATCGCTCTTCACTG } \\
\text { GCAGTACCGGCGGCGACACAGCTAGCGAGAAGTGACgatc }\end{array}$ & VMAAAVS IALHC \\
\hline 7 & $\mathrm{~S} 7 \mathrm{~T}$ & $\begin{array}{l}5^{\prime}->3,(+) \\
3{ }^{\prime}<-5,(-)\end{array}$ & $\begin{array}{l}\text { gatcCGTCATGGCCGCCGCTGCGACGATCGCTCTTCACTG } \\
\text { GCAGTACCGGCGGCGACGCTGCTAGCGAGAAGTGACgatc }\end{array}$ & VMAAAATIALHC \\
\hline 8 & I8A & $\begin{array}{l}5,->3,(+) \\
3^{\prime}<-5 \\
(-)\end{array}$ & $\begin{array}{l}\text { gatcCGTCATGGCCGCCGCTGCGTCGGCCGCTCTTCACTG } \\
\text { GCAGTACCGGCGGCGACGCAGCCGGCGAGAAGTGACgatc }\end{array}$ & VMAAAASAALHC \\
\hline 9 & $\mathrm{I} 8 \mathrm{H}$ & $\begin{array}{l}5^{\prime}->3^{\prime}(+) \\
3^{\prime}<-5,(-)\end{array}$ & $\begin{array}{l}\text { gatcCGTCATGGCCGCCGCTGCGTCGCACGCTCTTCACTG } \\
\text { GCAGTACCGGCGGCGACGCAGCGTGCGAGAAGTGACgatc }\end{array}$ & VMAAAASHALHC \\
\hline 10 & $\mathrm{I} 8 \mathrm{~L}$ & $\begin{array}{l}5^{\prime}->3^{\prime}(+) \\
3^{\prime}<-5,(-)\end{array}$ & $\begin{array}{l}\text { gatcCGTCATGGCCGCCGCTGCGTCGCTCGCTCTTCACTG } \\
\text { GCAGTACCGGCGGCGACGCAGCGAGCGAGAAGTGACgatc }\end{array}$ & VMAAAASLALHC \\
\hline 11 & I8V & $\begin{array}{l}5^{\prime}->3^{\prime}(+) \\
3^{\prime}<-5,(-)\end{array}$ & $\begin{array}{l}\text { gatcCGTCATGGCCGCCGCTGCGTCGGTCGCTCTTCACTG } \\
\text { GCAGTACCGGCGGCGACGCAGCCAGCGAGAAGTGACgatc }\end{array}$ & VMAAAASVALHC \\
\hline 12 & A9V & $\begin{array}{l}5,->3,(+) \\
3^{\prime}<-5,(-)\end{array}$ & $\begin{array}{l}\text { gatcCGTCATGGCCGCCGCTGCGTCGATCGTCCTTCACTG } \\
\text { GCAGTACCGGCGGCGACGCAGCTAGCAGGAAGTGACgatc }\end{array}$ & VMAAAAS IVLHC \\
\hline 13 & L10A & $\begin{array}{l}5,->3,(+) \\
3{ }^{\prime}<-5,(-)\end{array}$ & $\begin{array}{l}\text { gatcCGTCATGGCCGCCGCTGCGTCGATCGCTGCCCACTG } \\
\text { GCAGTACCGGCGGCGACGCAGCTAGCGACGGGTGACgatc }\end{array}$ & VMAAAAS IAAHC \\
\hline 14 & $\mathrm{~L} 10 \mathrm{~F}$ & $\begin{array}{l}5^{\prime}->33^{\prime}(+) \\
3^{\prime}<-5,(-)\end{array}$ & $\begin{array}{l}\text { gatcCGTCATGGCCGCCGCTGCGTCGATCGCTTTCCACTG } \\
\text { GCAGTACCGGCGGCGACGCAGCTAGCGAAAGGTGACgatc }\end{array}$ & VMAAAAS IAFHC \\
\hline 15 & L10Y & $\begin{array}{l}5^{\prime}->3^{\prime}(+) \\
3^{\prime}<-5,(-)\end{array}$ & $\begin{array}{l}\text { gatcCGTCATGGCCGCCGCTGCGTCGATCGCTTACCACTG } \\
\text { GCAGTACCGGCGGCGACGCAGCTAGCGAATGGTGACgatc }\end{array}$ & VMAAAAS IAYHC \\
\hline 16 & $\mathrm{H} 11 \mathrm{~T}$ & $\begin{array}{l}5^{\prime}->3,(+) \\
3{ }^{\prime}<-5,(-)\end{array}$ & $\begin{array}{l}\text { gatcCGTCATGGCCGCCGCTGCGTCGATCGCTCTTACCTG } \\
\text { GCAGTACCGGCGGCGACGCAGCTAGCGAGAATGGACgatc }\end{array}$ & VMAAAAS IALTC \\
\hline 17 & M2I-I8V & $\begin{array}{l}5^{\prime}->3^{\prime}(+) \\
3^{\prime}<-5,(-)\end{array}$ & $\begin{array}{l}\text { gatcCGTCATCGCCGCCGCTGCGTCGGTCGCTCTTCACTG } \\
\text { GCAGTAGCGGCGGCGACGCAGCCAGCGAGAAGTGACgatc }\end{array}$ & VIAAAASVALHC \\
\hline 18 & M2I-L10F & $\begin{array}{l}5,->3,(+) \\
3,<-5,(-)\end{array}$ & $\begin{array}{l}\text { gatcCGTCATCGCCGCCGCTGCGTCGATCGCTTTCCACTG } \\
\text { GCAGTAGCGGCGGCGACGCAGCTAGCGAAAGGTGACgatc }\end{array}$ & VIAAAAS IAFHC \\
\hline 19 & A4I-L10Y & $\begin{array}{l}5^{\prime}->3^{\prime}(+) \\
3^{\prime}<-5,(-)\end{array}$ & $\begin{array}{l}\text { gatcCGTCATGGCCATCGCTGCGtCGATCGCTTACCACTG } \\
\text { GCAGTACCGGTAGCGACGCAGCTAGCGAATGGTGACgatc }\end{array}$ & VMAIAAS IAYHC \\
\hline 20 & A6V-A9V & $\begin{array}{l}5^{\prime}->3^{\prime}(+) \\
3^{\prime}<-5,(-)\end{array}$ & $\begin{array}{l}\text { gatcCGTCATGGCCGCCGCTGTGTCGATCGTCCTTCACTG } \\
\text { GCAGTACCGGCGGCGACACAGCTAGCAGGAAGTGACgatc }\end{array}$ & VMAAAVS IVLHC \\
\hline 21 & S7T-L10F & $\begin{array}{l}5,->3,(+) \\
3,<-5,(-)\end{array}$ & $\begin{array}{l}\text { gatcCGTCATGGCCGCCGCTGCGACGATCGCTTTCCACTG } \\
\text { GCAGTACCGGCGGCGACGCTGCTAGCGAAAGGTGACgatc }\end{array}$ & VMAAAAT IAFHC \\
\hline 22 & I8V-L10F & $\begin{array}{l}5^{\prime}->3,(+) \\
3,<-5,(-)\end{array}$ & $\begin{array}{l}\text { gatcCGTCATGGCCGCCGCTGCGTCGGTCGCTTTCCACTG } \\
\text { GCAGTACCGGCGGCGACGCAGCCAGCGAAAGGTGACgatc }\end{array}$ & VMAAAASVAFHC \\
\hline 23 & M2I-I8V-L10F & $\begin{array}{l}5,->3,(+) \\
3,<-5,(-)\end{array}$ & $\begin{array}{l}\text { gatcCGTCATCGCCGCCGCTGCGTCGGTCGCTTTCCACTG } \\
\text { GCAGTAGCGGCGGCGACGCAGCCAGCGAAAGGTGACgatc }\end{array}$ & VIAAAASVAFHC \\
\hline 24 & A3I-I8V-L10Y & $\begin{array}{l}5^{\prime}->3^{\prime}(+) \\
3^{\prime}<-5,(-)\end{array}$ & $\begin{array}{l}\text { gatcCGTCATGATCGCCgctGCGTCGGTCGCTTACCACTG } \\
\text { GCAGTACTAGCGGCGACGCAGCCAGCGAATGGTGACgatc }\end{array}$ & VMIAAASVAYHC \\
\hline 25 & A4I-S7T-L10Y & $\begin{array}{l}5,->3,(+) \\
3,<-5,(-)\end{array}$ & $\begin{array}{l}\text { gatcCGTCATGGCCATCGCTGCGACGATCGCTTACCACTG } \\
\text { GCAGTACCGGTAGCGACGCTGCTAGCGAATGGTGACgatc }\end{array}$ & VMAIAATIAYHC \\
\hline 26 & A5I-I8V-L10Y & $\begin{array}{l}5^{\prime}->3,(+) \\
3{ }^{\prime}<-5,(-)\end{array}$ & $\begin{array}{l}\text { gatcCGTCATGGCCGCCATCGCGtCGGTCGCTTACCACTG } \\
\text { GCAGTACCGGCGGTAGCGCAGCCAGCGAATGGTGACgatc }\end{array}$ & VMAAIASVAYHC \\
\hline 27 & $\begin{array}{l}\text { S7T-I8V-L10F } \\
\text { (= Neothioviridamide) }\end{array}$ & $\begin{array}{l}5^{\prime}->3{ }^{\prime}(+) \\
3^{\prime}<-5,(-)\end{array}$ & $\begin{array}{l}\text { gatcCGTCATGGCCGCCGCTGCGACGGTCGCTTTCCACTG } \\
\text { GCAGTACCGGCGGCGACGCTGCCAGCGAAAGGTGACgatc }\end{array}$ & VMAAAATVAFHC \\
\hline 28 & S7T-I8V-L10Y & $\begin{array}{l}5^{\prime}->3^{\prime}(+) \\
3{ }^{\prime}<-5,(-)\end{array}$ & $\begin{array}{l}\text { gatcCGTCATGGCCGCCGCTGCGACGGTCGCTTACCACTG } \\
\text { GCAGTACCGGCGGCGACGCTGCCAGCGAATGGTGACgatc }\end{array}$ & VMAAAATVAYHC \\
\hline 29 & A3G-A4G-A5G-A6G & $\begin{array}{l}5,->3,(+) \\
3,<-5,(-)\end{array}$ & $\begin{array}{l}\text { gatcCGTCATGGGCGGCGGTGGGTCGATCGCTCTTCACTG } \\
\text { GCAGTACCCGCCGCCACCCAGCTAGCGAGAAGTGACgatc }\end{array}$ & VMGGGGSIALHC \\
\hline
\end{tabular}




\begin{tabular}{|c|c|c|c|c|c|c|}
\hline 30 & \multicolumn{2}{|l|}{ A5I-S7T-I8V-L10Y } & \multicolumn{2}{|c|}{$\begin{array}{l}5^{\prime}->3^{\prime},(+) \\
3^{\prime}<-5,(-)\end{array}$} & $\begin{array}{l}\text { gatcCGTCATGGCCGCCATCGCGACGGTCGCTTACCACTG } \\
\text { GCAGTACCGGCGGTAGCGCTGCCAGCGAATGGTGACgatC }\end{array}$ & VMAAIATVAYHC \\
\hline 31 & \multicolumn{2}{|c|}{$\begin{array}{l}\text { M2I-A3G-A4F-A6V-S7T-L10V } \\
\text { (= DSM44262) }\end{array}$} & \multicolumn{2}{|c|}{$\begin{array}{l}5^{\prime}->33^{\prime}(+) \\
3^{\prime}<-5,(-)\end{array}$} & $\begin{array}{l}\text { gatcCGTCATCGGCTTCGCTGTGACGATCGCTGTCCACTG } \\
\text { GCAGTAGCCGAAGCGACACTGCTAGCGACAGGTGACgatC }\end{array}$ & VIGFAVTIAVHC \\
\hline 32 & \multicolumn{2}{|c|}{$\begin{array}{l}\text { M2G-A3G-A4L-A5L-A6V-S7T } \\
\text {-I8P-L10T } \\
(=\text { CNT029) }\end{array}$} & \multicolumn{2}{|c|}{$\begin{array}{l}5^{\prime}->3^{\prime}(+) \\
3^{\prime}<-5,(-)\end{array}$} & $\begin{array}{l}\text { gatcCGTCGGCGGCCTCCTGGTGACGCCCGCTACGCACTG } \\
\text { GCAGCCGCCGGAGGACCACTGCGGGCGATGCGTGACgatc }\end{array}$ & VGGLLVTPATHC \\
\hline \multicolumn{7}{|c|}{ Neothioviridamide series } \\
\hline \multirow[t]{2}{*}{ No. } & Designation & \multicolumn{2}{|c|}{ strand } & & primer sequence & translated AA \\
\hline & Neothioviridamide & \multicolumn{2}{|c|}{$5^{\prime}->3^{\prime}(+)$} & gat & GTGATGGCGGCTGCCGCCACGGTGGCCTTCCACTGctag & VMAAAATVAFHC \\
\hline 2 & V8I & \multicolumn{2}{|c|}{$\begin{array}{l}5^{\prime}->3^{\prime},(+) \\
3^{\prime}<-5,(-)\end{array}$} & gat & $\begin{array}{l}\text { CGTCATGGCCGCCGCTGCGACGATCGCTTTCCACTG } \\
\text { GCAGTACCGGCGGCGACGCTGCTAGCGAAAGGTGACgatc }\end{array}$ & VMAAAATIAFHC \\
\hline 3 & F10Y & \multicolumn{2}{|c|}{$\begin{array}{l}5^{\prime}->3^{\prime},(+) \\
3^{\prime}<-5\end{array}$} & gat & $\begin{array}{l}\text { CGTCATGGCCGCCGCTGCGACGGTCGCTTACCACTG } \\
\text { GCAGTACCGGCGGCGACGCTGCCAGCGAATGGTGACgatc }\end{array}$ & VMAAAATVAYHC \\
\hline 4 & A5I-F10Y & \multicolumn{2}{|c|}{$\begin{array}{l}5^{\prime}->3^{\prime},(+) \\
3^{\prime}<-5 \\
(-)\end{array}$} & gat & $\begin{array}{l}\text { CGTCATGGCCGCCATCGCGACGGTCGCTTACCACTG } \\
\text { GCAGTACCGGCGTAGCGCTGCCAGCGAATGGTGACgatc }\end{array}$ & VMAAIATVAYHC \\
\hline 5 & V8I-F10L & \multicolumn{2}{|c|}{$\begin{array}{l}5^{\prime}->3^{\prime}(+) \\
3^{\prime}<-55^{\prime}(-)\end{array}$} & gat & $\begin{array}{l}\text { CGTCATGGCCGCCGCTGCGACGATCGCTCTTCACTG } \\
\text { GCAGTACCGGCGGCGACGCTGCTAGCGAGAAGTGACgatc }\end{array}$ & VMAAAATIALHC \\
\hline 6 & A4I-V8I-F10Y & \multicolumn{2}{|c|}{$\begin{array}{l}5^{\prime}->3^{\prime}(+) \\
3^{\prime}<-5,(-)\end{array}$} & gat & $\begin{array}{l}\text { CGTCATGGCCATCGCTGCGACGATCGCTTACCACTG } \\
\text { GCAGTACCGGTAGCGACGCTGCTAGCGAATGGTGACgatc }\end{array}$ & VMAIAATIAYHC \\
\hline 7 & $\begin{array}{l}\text { T7S-V8I-F10L } \\
\text { (= prethioviridamide) }\end{array}$ & \multicolumn{2}{|c|}{$\begin{array}{l}5^{\prime}->3^{\prime}(+) \\
3^{\prime}<-5,(-)\end{array}$} & gat & $\begin{array}{l}\text { CGTCATGGCCGCCGCTGCGTCGATCGCTCTTCACTG } \\
\text { GCAGTACCGGCGGCGACGCAGCTAGCGAGAAGTGACgatc }\end{array}$ & VMAAAAS IALHC \\
\hline 8 & T7S-V8M-F10L & \multicolumn{2}{|c|}{$\begin{array}{l}5^{\prime}->3^{\prime},(+) \\
3^{\prime}<-5,(-)\end{array}$} & gat & $\begin{array}{l}\text { CGTCATGGCCGCCGCTGCGTCGATGGCTCTTCACTG } \\
\text { GCAGTACCGGCGGCGACGCAGCTACCGAGAAGTGACgatc }\end{array}$ & VMAAAASMALHC \\
\hline 9 & $\begin{array}{l}\text { M2I-A3G-A4F- } \\
\text { A6V-V8I-F10V } \\
\text { (= DSM44262) }\end{array}$ & \multicolumn{2}{|c|}{$\begin{array}{l}5^{\prime}->3^{\prime}(+) \\
3^{\prime}<-55^{\prime}(-)\end{array}$} & gat & $\begin{array}{l}\text { CGTCATCGGCTTCGCTGTGACGATCGCTGTCCACTG } \\
\text { GCAGTAGCCGAAGCGACACTGCTAGCGACAGGTGACgatc }\end{array}$ & VIGEAVTIAVHC \\
\hline 10 & $\begin{array}{l}\text { M2G-A3G-A4L- } \\
\text { A5L-A6V-V8P-F10T } \\
(=\text { CNT029) }\end{array}$ & \multicolumn{2}{|c|}{$\begin{array}{l}5^{\prime}->33^{\prime}(+) \\
3^{\prime}<-55^{\prime}(-)\end{array}$} & & $\begin{array}{l}\text { GTCGGCGGCCTCCTGGTGACGCCCGCTACGCACTG } \\
\text { CAGCCGCCGGAGGACCACTGCGGGCGATGCGTGACgatc }\end{array}$ & VGGLLVTPATHC \\
\hline
\end{tabular}


Table S2. Designs and productivities of prethioviridamide derivatives

\begin{tabular}{|c|c|c|c|}
\hline No. & Designation $^{\mathrm{a}}$ & Core peptide $^{\mathrm{b}}$ & Productivity $^{\mathrm{c}}$ \\
\hline & prethioviridamide & VMAAAAS IALHC & $106 \mathrm{mg} / \mathrm{L}$ \\
\hline 1 & V1I & IMAAAAS IALHC & $44.9 \mathrm{mg} / \mathrm{L}$ \\
\hline 2 & $\mathrm{M} 2 \mathrm{~A}$ & VAAAAAS IALHC & $13.0 \mathrm{mg} / \mathrm{L}$ \\
\hline 3 & M2I & VIAAAAS IALHC & $10.0 \mathrm{mg} / \mathrm{L}$ \\
\hline 4 & M2L & VLAAAAS IALHC & $35.7 \mathrm{mg} / \mathrm{L}$ \\
\hline 5 & M2V & VVAAAAS IALHC & $6.4 \mathrm{mg} / \mathrm{L}$ \\
\hline 6 & A6V & VMAAAVS IALHC & $45.4 \mathrm{mg} / \mathrm{L}$ \\
\hline 7 & S7T & VMAAAAT IALHC & $(+)$ \\
\hline 8 & I8A & VMAAAASAALHC & $18.5 \mathrm{mg} / \mathrm{L}$ \\
\hline 9 & $\mathrm{I} 8 \mathrm{H}$ & VMAAAAS HALHC & $3.1 \mathrm{mg} / \mathrm{L}$ \\
\hline 10 & I8L & VMAAAAS LALHC & $17.9 \mathrm{mg} / \mathrm{L}$ \\
\hline 11 & I8V & VMAAAASVALHC & $74.5 \mathrm{mg} / \mathrm{L}$ \\
\hline 12 & A9V & VMAAAAS IVLHC & $50.7 \mathrm{mg} / \mathrm{L}$ \\
\hline 13 & L10A & VMAAAAS IAAHC & $0.62 \mathrm{mg} / \mathrm{L}$ \\
\hline 14 & L10F & VMAAAAS IAFHC & $11.6 \mathrm{mg} / \mathrm{L}$ \\
\hline 15 & L10Y & VMAAAAS IAYHC & $2.7 \mathrm{mg} / \mathrm{L}$ \\
\hline 16 & $\mathrm{H} 11 \mathrm{~T}$ & VMAAAAS IALTC & $(+)$ \\
\hline 17 & M2I-I8V & VIAAAASVALHC & $13.1 \mathrm{mg} / \mathrm{L}$ \\
\hline 18 & M2I-L10F & VIAAAAS IAFHC & $10.9 \mathrm{mg} / \mathrm{L}$ \\
\hline 19 & A4I-L10Y & VMAIAAS IAYHC & $(+)$ \\
\hline 20 & A6V-A9V & VMAAAVS IVLHC & $0.15 \mathrm{mg} / \mathrm{L}$ \\
\hline 21 & S7T-L10F & VMAAAATIAFHC & $(+)$ \\
\hline 22 & I8V-L10F & VMAAAASVAFHC & $26.6 \mathrm{mg} / \mathrm{L}$ \\
\hline 23 & M2I-I8V-L10F & VIAAAASVAFHC & $20.6 \mathrm{mg} / \mathrm{L}$ \\
\hline 24 & A3I-I8V-L10Y & VMIAAASVAYHC & - \\
\hline 25 & A4I-S7T-L10Y & VMAIAATIAYHC & $(+)$ \\
\hline 26 & A5I-I8V-L10Y & VMAAIASVAYHC & $(+)$ \\
\hline 27 & $\begin{array}{l}\text { S7T-I8V-L10F } \\
\text { (Neothioviridamide) }\end{array}$ & VMAAAATVAFHC & $(+)$ \\
\hline 28 & S7T-I8V-L10Y & VMAAAATVAYHC & $(+)$ \\
\hline 29 & A3G-A4G-A5G-A6G & VMGGGGS IALHC & - \\
\hline 30 & A5I-S7T-I8V-L10Y & VMAAIATVAYHC & $(+)$ \\
\hline 31 & $\begin{array}{l}\text { M2I-A3G-A4F-A6V-S7T-L10V } \\
\text { (= DSM44262) }\end{array}$ & VIGFAVTIAVHC & - \\
\hline 32 & $\begin{array}{l}\text { M2G-A3G-A4L-A5L-A6V-S7T-I8P-L10T } \\
\text { (= CNT029) }\end{array}$ & VGGLLVTPATHC & - \\
\hline
\end{tabular}

\footnotetext{
a Those mimicking or partially mimicking the core peptide sequence of thioviridamide-like compounds (= genome-inspired) are shown in bold.

${ }^{\mathrm{b}}$ Substituted residues are colored in red.

${ }^{\mathrm{c}}(+)$, only detected by MS; -, not detected.
} 
Table S3. Designs and productivities of neothioviridamide derivatives

\begin{tabular}{|c|c|c|c|}
\hline No. & Designation $^{\mathrm{a}}$ & Core peptide ${ }^{\mathrm{b}}$ & Productivity $^{\mathrm{c}}$ \\
\hline & Neothioviridamide & VMAAAATVAFHC & $20.9 \mathrm{mg} / \mathrm{L}$ \\
\hline 1 & T7S & VMAAAASVAFHC & $0.97 \mathrm{mg} / \mathrm{L}$ \\
\hline 2 & V8I & VMAAAAT IAFHC & $5.0 \mathrm{mg} / \mathrm{L}$ \\
\hline 3 & F10Y & VMAAAATVAYHC & $6.2 \mathrm{mg} / \mathrm{L}$ \\
\hline 4 & A5I-F10Y & VMAAIATVAYHC & $(+)$ \\
\hline 5 & V8I-F10L & VMAAAATIALHC & $22.5 \mathrm{mg} / \mathrm{L}$ \\
\hline 6 & A4I-V8I-F10Y & VMAIAATIAYHC & $(+)$ \\
\hline 7 & T7S-V8I-F10L (= prethioviridamide) & VMAAAAS IALHC & $(+)$ \\
\hline 8 & T7S-V8M-F10L & VMAAAASMALHC & - \\
\hline 9 & $\begin{array}{l}\text { M2I-A3G-A4F-A6V-V8I-F10V } \\
\text { (= DSM44262) }\end{array}$ & VIGFAVTIAVHC & - \\
\hline 10 & $\begin{array}{l}\text { M2G-A3G-A4L-A5L-A6V-V8P-F10T } \\
\text { (= CNT029) }\end{array}$ & VGGLLVTPATHC & - \\
\hline \multicolumn{4}{|c|}{$\begin{array}{l}\text { Those mimicking or partially mimicking the core peptide sequence of thioviridamide-like compounds }(= \\
\text { genome-inspired) are shown in bold. }\end{array}$} \\
\hline
\end{tabular}




\section{Reference}

(1) Komatsu, M.; Uchiyama, T.; Omura, S.; Cane, D. E.; Ikeda, H. Genome-Minimized Streptomyces Host for the Heterologous Expression of Secondary Metabolism. Proc. Natl. Acad. Sci. U. S. A. 2010, 107 (6), 26462651.

(2) Cane, D. E.; He, X.; Kobayashi, S.; Omura, S.; Ikeda, H. Geosmin Biosynthesis in Streptomyces Avermitilis. Molecular Cloning, Expression, and Mechanistic Study of the Germacradienol/Geosmin Synthase. $J$. Antibiot. (Tokyo). 2006, 59 (8), 471-479.

(3) Izumikawa, M.; Kozone, I.; Hashimoto, J.; Kagaya, N.; Takagi, M.; Koiwai, H.; Komatsu, M.; Fujie, M.; Satoh, N.; Ikeda, H.; Shin-ya, K. Novel Thioviridamide Derivative - JBIR-140: Heterologous Expression of the Gene Cluster for Thioviridamide Biosynthesis. J. Antibiot. (Tokyo). 2015, 68 (8), 533-536.

(4) Kawahara, T.; Izumikawa, M.; Kozone, I.; Hashimoto, J.; Kagaya, N.; Koiwai, H.; Komatsu, M.; Fujie, M.; Sato, N.; Ikeda, H.; Shin-ya, K. Neothioviridamide, a Polythioamide Compound Produced by Heterologous Expression of a Streptomyces Sp. Cryptic RiPP Biosynthetic Gene Cluster. J. Nat. Prod. 2018, 81 (2), 264269.

(5) Miyamoto, K. T.; Komatsu, M.; Ikeda, H. Discovery of Gene Cluster for Mycosporine-Like Amino Acid Biosynthesis from Actinomycetales Microorganisms and Production of a Novel Mycosporine-Like Amino Acid by Heterologous Expression. Appl. Environ. Microbiol. 2014, 80 (16), 5028-5036.

(6) Kim, J. H.; Komatsu, M.; Shin-ya, K.; Omura, S.; Ikeda, H. Distribution and Functional Analysis of the Phosphopantetheinyl Transferase Superfamily in Actinomycetales Microorganisms. Proc. Natl. Acad. Sci. 2018, 115 (26), 6828-6833.

(7) Gibson, D. G.; Young, L.; Chuang, R.-Y.; Venter, J. C.; Hutchison, C. A.; Smith, H. O. Enzymatic Assembly of DNA Molecules up to Several Hundred Kilobases. Nat. Methods 2009, 6 (5), 343-345. 